\title{
Una nueva visión del mundo: la ecología profunda y su incipiente recepción en el derecho nacional e internacional. (Segunda parte)
}

\section{A New Vision of the World: Deep Ecology and its incipient reception in National and International Law. (Second Part)}

Adriana Norma Martínez,* Adriana Margarita Porcelli**

DOI: http://dx.doi.org/10.21503/lex.v16i21.1553

* Abogada, escribana, posgraduada en Derecho del Turismo UBA. Magíster en Ambiente Humano, UNLZ. Profesora adjunta regular, Departamento de la Facultad de Derecho Universidad de Buenos Aires. Jefa de la División Derecho. Profesora asociada ordinaria de la Universidad Nacional de Luján.

Correo electrónico: info@anmart.com.ar

** Abogada UBA. Magíster en Relaciones Internacionales, Universidad Maimónides. Diplomada en Derechos Económicos, Sociales y Culturales, UNPSJB. Profesora Adjunta Ordinaria, División Derecho de la Universidad Nacional de Luján.

Correo electrónico: adporcelli@yahoo.com.ar

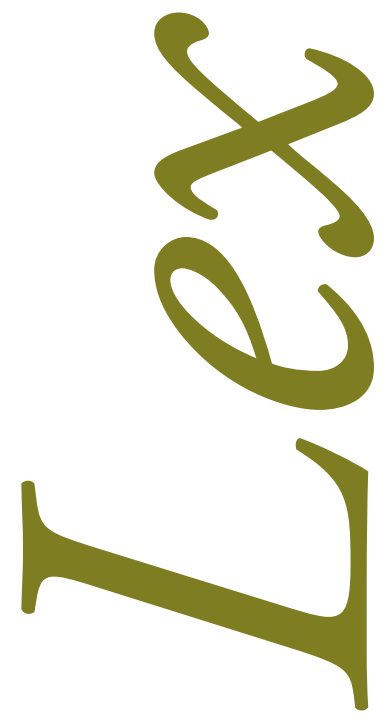




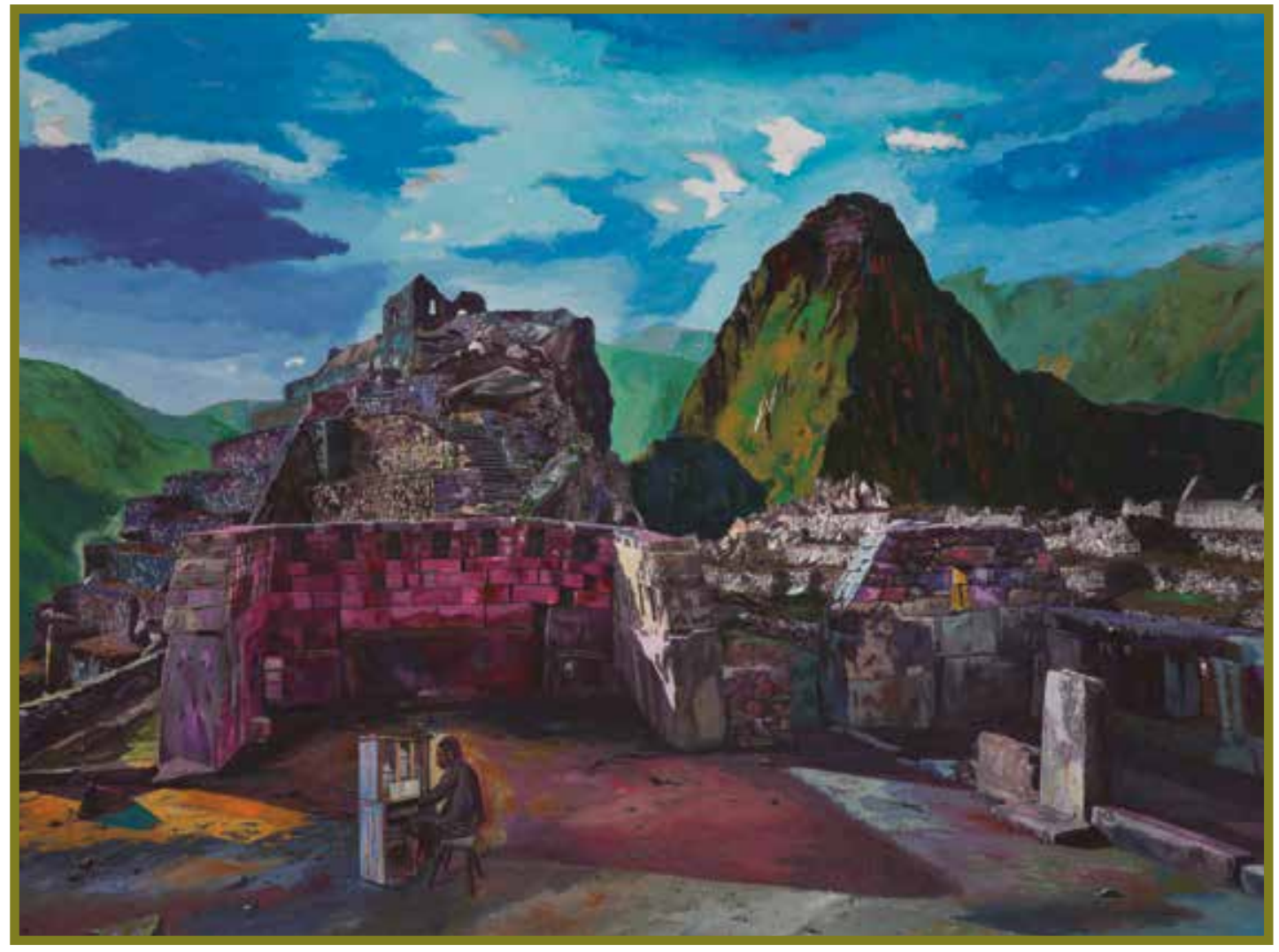

Machupicchu. Enrique Polanco.

https://www.facebook.com/enriquepolancopintor/ 


\section{RESUMEN}

El presente trabajo forma parte de un proyecto de investigación que tiene por objeto el desarrollo de las diferentes posturas filosóficas, éticas y científicas que consideran a la naturaleza y a todos los seres vivientes como poblaciones o entidades con vida propia rescatando su valor intrínseco, y en consecuencia dan fundamento a concepciones jurídicas que los categorizan como sujetos de derechos y el análisis de las escasas legislaciones y casos jurisprudenciales nacionales e internacionales que la han receptado. Dada la extensión y profundidad de la temática, la misma se expone en tres partes, y el presente artículo constituye la segunda parte, consistente en el análisis de los escasos instrumentos jurídicos que a nivel internacional y regional han categorizado a la naturaleza como un nuevo sujeto de derechos.

Palabras clave: ecología profunda, derechos de la naturaleza, personería jurídica, seres sintientes, sujeto de derechos.

\section{ABSTRACT}

The present work is part of a research project whose purpose is the development of the different philosophical, ethical and scientific positions that consider nature and all living beings as populations or entities with their own life rescuing their intrinsic value and consequently, give ground to legal concepts that categorize them as subjects of rights and the analysis of the few national and international laws and jurisprudential cases that have received it. Given the extent and depth of the topic, it is exposed in three parts and this article constitutes the second part of the analysis of the scarce legal instruments that have categorized nature as a new subject of rights at the regional and international level.

Key words: deep ecology, rights of nature, legal status, sentient beings, subject of rights. 


\section{INTRODUCCIÓN}

En la primera parte del trabajo se desarrollaron detenidamente las diferentes posturas científicas, éticas y filosóficas modernas que fundamentan la tesis jurídica de la naturaleza como sujeto de derechos, cada una de ellas con sus diferentes enfoques o variantes, clasificándolas desde el punto de vista científico (la ecología, la revolución de la física, la biología y sus implicancias en la ética y la filosofía), desde el punto de vista jurídico, ecológico-jurídico y desde la filosofía del derecho y la teoría ancestral: Madre Tierra o Pachamama. ${ }^{1}$ Muchas de estas teorías fueron recientemente receptadas tanto a nivel internacional y regional —en documentos no vinculantes - como a nivel interno, en las noveles legislaciones de algunos países, así como se están abriendo camino en las sentencias de varios jueces y cortes nacionales. En el presente artículo, utilizando el método deductivo y analítico se profundizará en el estudio de los instrumentos jurídicos a nivel internacional y regional, y como puntapié inicial, la Carta Mundial de la Naturaleza de las Naciones Unidas de 1982, la Carta de la Tierra del 2000, la Declaración Universal de los Derechos de los Animales, la Declaración Universal de los Derechos de la Madre Tierra del 2010, el Tribunal Ético Permanente de los Derechos de la Naturaleza en el 2014 y el Proyecto de Declaración Universal de los Derechos de los Ríos.

\section{INSTRUMENTOS JURÍDICOS A NIVEL INTERNACIONAL}

\section{Naciones Unidas}

\subsection{Carta Mundial de la Naturaleza}

En el marco de las Naciones Unidas, en el año 1982, se dictó la Carta Mundial de la Naturaleza, considerada como el puntapié inicial en el reconocimiento de los derechos de la naturaleza y de su valor intrínseco, independientemente del beneficio para el hombre. El documento, que no es un tratado, no tiene la fuerza vinculante; sin embargo, expresa una fuerte

1 La primera parte de la investigación se puede consultar en Adriana Norma Martínez y Adriana Margarita Porcelli, "Una nueva visión del mundo: la ecología profunda y su incipiente recepción en el derecho nacional e internacional (primera parte)", Lex año XV-I, n. 20 (2017): 395-440, ISSN 2313-1861, http://dx.doi.org/10.21503/lex.v15i20.1450 
convicción en la protección de la naturaleza y la obligación moral asumida por los Estados que votaron a su favor. La Carta tiene sus orígenes en la estrategia mundial de conservación de la naturaleza, elaborada por la Unión Internacional para la Conservación de la Naturaleza (UICN) con el apoyo del Programa de las Naciones Unidas para el Medio Ambiente (PNUMA) y del Fondo Mundial para la Naturaleza (WWF). Contiene un preámbulo en el cual la Asamblea General asume una serie de convicciones generales acerca del valor intrínseco de todos los seres vivos, cualquiera que sea la utilidad de estos para el hombre, también así se muestra consciente que la especie humana es parte de la naturaleza, que la vida depende del funcionamiento ininterrumpido de los sistemas naturales que son fuente de energía y materias nutritiva y que la civilización tiene sus raíces en la naturaleza. Asimismo, alerta respecto del deterioro de los sistemas naturales que dimanan del consumo excesivo, del abuso de los recursos naturales y de la falta de un orden económico adecuado. Textualmente afirma: "Convencida de que: a) Toda forma de vida es única y merece ser respetada, cualquiera que sea su utilidad para el hombre, y con el fin de reconocer a los demás seres vivos su valor intrínseco, el hombre ha de guiarse por un código de acción moral". ${ }^{2}$

\subsection{Resoluciones de las Naciones Unidas. Día Internacional de la Madre Tierra. Armonía con la Naturaleza}

Muy variados han sido los esfuerzos desde algunos Estados, organizaciones internacionales y hasta de la sociedad civil para el reconocimiento internacional de los derechos de la naturaleza. Esos esfuerzos se remontan y reconocen su origen en el estallido de un pozo de petróleo en Santa Bárbara, California, en 1969, considerado el mayor desastre ecológico en aguas estadounidenses. Ya antes de esa fecha, en 1962, Rachel Carson en su libro Silent Spring (Primavera Silenciosa) instauró, en la opinión pública, tópicos pioneros como ciencias ambientales, el peligro de los plaguicidas, el macrotema de la contaminación y la salud pública. El 22 de abril de 1970, más de 20 millones de habitantes invadieron calles, parques y auditorios, para manifestar su preocupación por la ecología, por lo cual esa fecha se considera como el día inicial de los movimientos ambientalistas en todo el mundo. ${ }^{3}$ Treinta y nueve ańos después, el presidente de Bolivia, Evo Morales, presentó, el 20 de abril de 2009 a la Asamblea General de las Naciones Unidas, una propuesta de Declaración Universal de los Derechos de la Madre Tierra. Si bien el proyecto no prosperó, en el sexagésimo tercer período de sesiones celebrado el día 22 de abril, se aprobó por unanimidad, por Resolución No 63/278 del $1^{\circ}$ de mayo de 2009, que todo 22 de abril sea celebrado como el "Día Internacional de la Madre Tierra". ${ }^{4}$ En

\footnotetext{
ONU, "Carta Mundial de la Naturaleza”, 28 de octubre de 1982. A/37/L.4 y Add.1, 2.

3 "Día de la Tierra: la alfabetización ambiental y climática es la cura”, Infobae (21 de abril de 2017), sección RSE\&Sustentabilidad, acceso el 1 de agosto de 2017, http://www.infobae.com/economia/rse/2017/04/21/dia-de-la-tierra-la-alfabetizacion-ambiental-y-climatica-es-la-cura/

4 Los Días Internacionales tienen por objeto sensibilizar, concienciar, llamar la atención, señalar que existe un problema sin resolver, un asunto importante y pendiente en las sociedades para que, a través de esa sensibilización, los Gobiernos y los Estados actúen y tomen medidas o para que los ciudadanos así lo exijan a sus representantes.
} 
la resolución se efectúa una afirmación relevante: "Reconociendo también que Madre Tierra es una expresión común utilizada para referirse al planeta Tierra en diversos países y regiones, lo que demuestra la interdependencia existente entre los seres humanos, las demás especies vivas y el planeta que todos habitamos". ${ }^{5}$ Nótese que no se trata del Día de la Tierra, sino del Día de la Madre Tierra. Una cosa es decir Tierra, como un objeto que se puede comprar, vender, investigar científicamente y explotar económicamente y otra muy diferente es decir Madre Tierra, porque a una madre no se la puede explotar económicamente, ni mucho menos comprar o vender. El 21 de diciembre de 2009, la Asamblea General de Naciones Unidas aprueba la Resolución No64/196 Armonía con la Naturaleza. En ella expresa su preocupación por el deterioro ambiental y los impactos negativos en la naturaleza resultantes de la actividad humana, recuerda la Carta Mundial de la Naturaleza de 1982 y manifiesta su convencimiento de que la humanidad puede y debería vivir en armonía con la naturaleza. ${ }^{6}$

El Foro Permanente para las Cuestiones Indígenas, órgano asesor del Consejo Económico y Social de las Naciones Unidas, publicó un estudio sobre la necesidad de reconocer y respetar los derechos de la Madre Tierra. En el mismo manifestó que en el año 2009, la Asamblea General de las Naciones Unidas, en su sexagésimo cuarto período de sesiones, se ha ocupado, entre otras materias, del ambiente, del desarrollo sostenible, la biodiversidad, el cambio climático, la desertificación, el agua como recurso vital, y también de la Resolución Armonía con la Naturaleza. ${ }^{7}$ El estudio continúa afirmando que los pueblos indígenas que abrigaban la concepción de la naturaleza como Madre Tierra dotada de derechos tienen también el derecho de hacerla llegar a los foros estatales e internacionales. Destaca que la Madre Tierra, conceptualizada en los Andes, constituye un marco referencial que permite recopilar y desarrollar una visión universal compartida por una diversidad de culturas, en particular las indígenas. El pueblo mapuche, cuyo territorio original se encuentra en la zona meridional de Argentina y Chile, se considera a sí mismo "gente de la tierra". ${ }^{8}$ Este pueblo, en conjunto se imagina hijos e hijas de la tierra, un brote de la tierra, nacidos de ella, gente que nace, vive, transita, protege y al morir vuelve a la Tierra. De igual manera, en el pensamiento guaraní el caminar hacia la Tierra sin Mal es el marco de la existencia y de la continuidad cultural, para lo que es importante el cumplimiento del derecho; de lo contrario, se enfrentan situaciones de desequilibrio ecológico, social y económico para la comunidad. Si el desequilibrio es profundo hasta puede desaparecer la comunidad y tener entonces que recomponerse. También

5 Asamblea General de las Naciones Unidas, "Resolución aprobada por la Asamblea General el 22 de abril de 2009 $\mathrm{N}^{\circ}$ 63/278. Día Internacional de la Madre Tierra”, sexagésimo tercer período de sesiones (1 de mayo de 2009, A/ RES/63/278), 1-2.

6 Asamblea General de las Naciones Unidas, "Resolución aprobada por la Asamblea General el 21 de diciembre de 2009 No 64/196. Armonía con la Naturaleza". Sexagésimo cuarto período de sesiones (12 de febrero de 2010, A/RES/64/196), 2.

7 El Estado Plurinacional de Bolivia fue el promotor de tal Resolución, pero la propuesta boliviana empleaba el término "Madre Tierra", el cual traducía el concepto andino de Pachamama.

8 Mapa-che: mapa es tierra, en tanto que che es gente. 
se refiere a los derechos de la Madre Tierra en medios no indígenas, tomando en cuenta las teorías que fueron desarrolladas en la primera parte de este trabajo. En síntesis, menciona a Aldo Leopold, a James Lovelock con la hipótesis de Gaia y al movimiento de la ecología profunda promovido por Arne Naess. En base a lo anteriormente señalado, en el informe se vislumbra un cambio de paradigma. Desde la Carta Mundial de la Naturaleza de 1982, la ONU reconoce que la humanidad es una de las especies constitutivas de la naturaleza y que su propia existencia guarda dependencia con ella, así como que toda forma de vida tiene un valor intrínseco y merece, por tanto, cualquiera que sea su utilidad, el debido respeto por parte de la especie humana. No en vano la reciente Resolución sobre Armonía con la Naturaleza menciona como antecedente en primer lugar la Carta Mundial de la Naturaleza, con la cual sintoniza muy directamente. ${ }^{9}$ Conforme lo solicitado por la Asamblea General, el Secretario General de las Naciones Unidas elaboró en año 2012 un informe titulado Armonía con la Naturaleza, que se centra en la evolución de la relación entre la humanidad y la naturaleza y presenta recomendaciones concretas para facilitar el examen ulterior del tema por los Estados miembros. En el mismo, destaca que las últimas teorías científicas ofrecen un nuevo entendimiento de la relación entre los seres humanos y su entorno. El supuesto que la especie humana es distinta e inherentemente superior a otras formas de vida o que tiene una función privilegiada en el cosmos carece de base científica, sin embargo, hay fundamentos para creer que, como miembros de la familia humana y el colectivo de los seres vivos, la humanidad tiene el deber de utilizar su capacidad y empatía para favorecer todas las formas de vida y que actúe como guardianes de la Tierra, en lugar de como sus dueños. Es interesante el cambio de visión que el secretario general manifiesta en este informe, considerando que un cambio de este tipo es fundamental para la supervivencia en todos los niveles, incluidos el ambiental, el social y el económico. Para ilustrar la situación actual, subraya la afirmación de Thomas Berry referida a que, en el siglo XX, la gloria de la humanidad se ha convertido en la desolación de la Tierra, y esa desolación se está convirtiendo en el destino de la humanidad. En consecuencia, recomienda a la Asamblea General que visibilice, a través del sitio web relativo a la Armonía con la Naturaleza, la labor que se está realizando en cumplimiento del párrafo 40 del documento "El futuro que queremos" a fin de desarrollar enfoques holísticos e integrados del desarrollo sostenible que lleven a la humanidad a vivir en armonía con la naturaleza y que conduzcan a la adopción de medidas para restablecer la salud y la integridad del sistema Tierra. ${ }^{10}$ Posteriormente se fueron sucediendo diferentes Resoluciones sobre Armonía con la Naturaleza, entre las que se destaca la Resolución No 67/214, del año 2013, que acoge con beneplácito el lanzamiento del sitio web sobre la armonía con la naturaleza y reconoce que el

9 Consejo Económico y Social. Foro Permanente para las Cuestiones Indígenas, "Estudio sobre la necesidad de reconocer y respetar los derechos de la Madre Tierra” (15 de enero de 2010, E/C.19/2010/4), 8-15.

10 Asamblea General de las Naciones Unidas, "Informe del Secretario General. Armonía con la Naturaleza", sexagésimo séptimo período de sesiones (17 de agosto de 2012 A/67/317), 4-14. 
planeta Tierra y sus ecosistemas son el hogar de la humanidad, que la "Madre Tierra" es una expresión común en muchos países y regiones y que algunos países reconocen los derechos de la naturaleza en el contexto de la promoción del desarrollo sostenible. ${ }^{11}$

A través de la Agenda 2030 de Desarrollo Sostenible, los Estados miembros han reafirmado que el planeta Tierra y sus ecosistemas son el hogar de la humanidad y que la "Madre Tierra” es una expresión corriente en muchos países y regiones. El 21 de abril de 2017, vísperas del Día Internacional de la Madre Tierra, varios países latinoamericanos instaron en la ONU a aprobar una Declaración Universal sobre los Derechos de la Madre Tierra, similar a la de los Derechos Humanos. Propusieron un marco jurídico que permita proteger los recursos naturales y asegurar el bienestar de la humanidad. Si bien el subsecretario de asuntos económicos y sociales de la ONU, Wu Hongbo, destacó el esfuerzo de muchos países para otorgar personería jurídica a la naturaleza tales como Ecuador, Bolivia y la Ciudad de México, la iniciativa no prosperó. ${ }^{12}$

\section{Carta de la Tierra}

Entre las muchas recomendaciones incluidas en el informe Nuestro Futuro Común de la Comisión Mundial de Medio Ambiente y Desarrollo — conocida como la Comisión Brundtland - se encuentra un llamado a la creación de una "Declaración Universal sobre la Protección Ambiental y el Desarrollo Sostenible" en la forma de una "nueva Carta" cuyos principios guíen a las naciones en la transición hacia el desarrollo sostenible. Con base en esta recomendación, Maurice F. Strong propuso, en 1990, que durante la Cumbre de la Tierra -Conferencia de las Naciones Unidas sobre el Medio Ambiente y el Desarrollo, celebrada en Río de Janeiro en 1992 - se redactara y adoptara la Carta de la Tierra, pero no se logró un acuerdo con respecto a sus principios. La Declaración de Río se convirtió en la declaración del consenso logrado en ese momento. En 1994, Maurice Strong — secretario general de la mencionada cumbre y presidente del Consejo de la Tierra — y Mijaíl Gorbachov — presidente de Green Cross International- decidieron retomar la elaboración de una Carta de la Tierra, con el apoyo de Ruud Lubbers — primer ministro del Gobierno de los Países Bajos- como una iniciativa de la sociedad civil. Luego de numerosos borradores y de considerar el aporte de personas de todas las regiones del mundo, la Comisión de la Carta de la Tierra logró un consenso sobre el texto final de la Carta de la Tierra, que se aprobó en marzo del 2000, en una reunión que se llevó a cabo en la sede de la Organización para la Educación, la Ciencia y la Cultura de las Naciones Unidas (UNESCO), en París, y posteriormente fue lanzada formalmente en

11 Asamblea General de las Naciones Unidas, "Resolución aprobada por la Asamblea General el 21 de diciembre de 2012 No 67/214. Armonía con la Naturaleza”, sexagésimo séptimo período de sesiones (15 de marzo de 2013 A/RES/67/214), 3.

12 ONU, "La protección de la Madre Tierra, a debate en la ONU", Noticias ONU (21 de abril de 2017), acceso el 5 de febrero de 2018, http://www.un.org/sustainabledevelopment/es/2017/04/la-proteccion-de-la-madre-tierra-a-debate-en-la-onu/ 
ceremonia en el Palacio de Paz en La Haya, con la presencia de la reina de Holanda. Desde sus primeros años, la Carta de la Tierra trató de promover un proceso de transformación, de crear una conciencia de ciudadanía global y un sentido de responsabilidad universal, a la par que se fue desarrollando una extensa red colectiva internacional conocida como la Iniciativa de la Carta de la Tierra. Esta Carta no es, pues, algo cerrado y finalizado en el 2000, sino un punto de partida para esa iniciativa.

En octubre del 2003, la XXXII Conferencia General de la UNESCO adoptó una resolución reconociendo a la Carta de la Tierra como un importante marco ético para el desarrollo sostenible. En noviembre del 2004, durante el Congreso Mundial para la Conservación en Bangkok, la Unión Internacional para la Conservación de la Naturaleza y los Recursos Naturales (UICN) aprobó una resolución reconociendo a la Carta de la Tierra como una guía ética para las políticas de la UICN y estimulando a sus Estados miembros para que determinen el papel que la Carta de la Tierra pueda desempeñar como guía para las políticas dentro de sus propias esferas de responsabilidad. ${ }^{13}$ También ejerció una influencia muy importante en el Plan de Implementación del Decenio de las Naciones Unidas de la Educación para el Desarrollo Sostenible (2005-2014), y la Carta de la Tierra Internacional ${ }^{14}$ estableció una alianza de trabajo con la UNESCO para promover el decenio. Sin embargo, todavía no se logró su reconocimiento formal por parte de la Asamblea General de las Naciones Unidas. La Carta de la Tierra es una declaración de principios éticos fundamentales para la construcción de una sociedad global justa, sostenible y pacífica en el Siglo XXI. Busca inspirar en todas las personas un nuevo sentido de interdependencia global y de responsabilidad compartida, a la vez que identifica una serie de actitudes y valores ampliamente compartidos, los cuales pueden fortalecer el compromiso con sus principios éticos. En cuanto a su estructura, contiene un preámbulo, 16 principios principales, 61 principios de apoyo y una conclusión intitulada "El Camino hacia Adelante". El Preámbulo afirma que "somos una sola familia humana y una sola comunidad terrestre con un destino común" y exhorta a todas las personas a reconocer su responsabilidad compartida, según su situación o capacidad, por el bienestar de toda la familia humana, la gran comunidad de la vida y las futuras generaciones. En reconocimiento a la interrelación existente entre los problemas ambientales, económicos, sociales y culturales de la humanidad, la Carta de la Tierra presenta un marco ético inclusivo e integral. Los títulos de las cuatro secciones en que se dividen los principios señalan el alcance de esta visión: I. Respeto y Cuidado de la Comunidad de Vida; II. Integridad Ecológica; III. Justicia Social y

13 Klaus Bosselmann y Prue Taylor, "La importancia de la Carta de la Tierra en el derecho internacional", en La Carta de la Tierra en acción: hacia un mundo sostenible, ed. por Peter Blaze Corcoran, Mirian Vilela y Alide Roerink (Ámsterdam: KIT Publisher BV, 2008), 178-180

14 La Carta de la Tierra Internacional - CTI - se creó en el 2006 como parte de un importante proceso de reorganización y ampliación de las actividades de la Carta de la Tierra. Está formada por el Consejo y la Secretaría de la CTI, y la misma existe para fomentar la misión y la visión de la Carta de la Tierra. 
Económica; y IV. Democracia, No Violencia y Paz. A la luz de su legitimidad, una creciente cantidad de juristas internacionales reconoce que la Carta de la Tierra está adquiriendo un estatus de soft law - ley blanda-. La característica de este tipo de documentos es que son moralmente vinculantes para los Gobiernos estatales que aceptan avalarlos y adoptarlos, aunque no son jurídicamente obligatorios y, por lo general, establecen la base para el desarrollo de hard law - ley dura - que sí es jurídicamente vinculante. En el Preámbulo y bajo el título: "La Tierra, nuestro hogar" destaca que la humanidad es parte de un vasto universo evolutivo y que la Tierra está viva con una comunidad singular de vida y que ha brindado las condiciones esenciales para su evolución. La capacidad de recuperación de la comunidad de vida y el bienestar de la humanidad dependen de la preservación de una biosfera saludable, con una rica variedad de plantas y animales, tierras fértiles, aguas puras y aire limpio. Así vemos que las cuatro grandes tendencias de la ecología que diferencia Boff —el ambiental, el social, el profundo y el integral— se encuentran reflejadas de forma conjunta en el Preámbulo. La visión ambiental se enriquece al incluir al ambiente en "la comunidad de la vida". La Tierra misma se presenta como que está "viva con una comunidad singular de vida" (Preámbulo, segundo párrafo), abrazando el concepto de Gaia, que constituye un organismo viviente excepcional, concepto que ha ido ganando cada vez más aceptación en la comunidad científica mundial. La ecología social surge en los siguientes temas: justicia social y económica, democracia, no violencia y paz, y la profunda aparece en el quinto párrafo del Preámbulo cuando se refiere a "un sentido de responsabilidad universal", al "espíritu de solidaridad humana", a la "reverencia ante el misterio del ser, con gratitud por el regalo de la vida y con humildad con respecto al lugar que ocupa el ser humano en la naturaleza". Finalmente, la ecología integral es expresada en el segundo párrafo del Preámbulo al definir a los seres humanos como "parte de un vasto universo evolutivo" y que "la Tierra ha brindado las condiciones esenciales para la evolución de la vida". ${ }^{15}$ Si se quiere resumir en una sola frase la gran propuesta política, ética, espiritual y cultural de la Carta de la Tierra, esa frase sería "modo de vida sostenible", en el entendimiento de que los seres humanos y la tierra tienen el mismo destino y que enfrentan el futuro juntos, no separados. Por ello, deberán protegerse entre sí con el fin de garantizar un futuro común; de lo contrario, ambos corren el riesgo de perecer. A este respecto, en su primera parte — Respeto y cuidado de la comunidad de la vida - notamos que dice "comunidad de la vida" en lugar de decir simplemente "vida". Boff explica que, de acuerdo con las ciencias de la Tierra y la biología moderna, todos los seres vivientes, desde la bacteria más primitiva, hasta las plantas, animales y seres humanos, básicamente portan el mismo código genético. Por lo tanto, todos están emparentados y son hermanos y hermanas. Lo que realmente existe no es el ambiente, sino la comunidad de la vida, en la que todos los seres son interdependientes y están entrelazados en inter-retro-relaciones, garantizando así la

15 Secretaría Internacional de la Carta de la Tierra, Iniciativa de la Carta de la Tierra. Folleto Informativo (San José de Costa Rica: Secretaria Internacional de la Carta de la Tierra, 2008), 73-79. 
biodiversidad y la sostenibilidad para todos, incluyendo a los más débiles. El ser humano es un subcapítulo del capítulo de la vida, tan solo un eslabón en esta cadena vital y un miembro singular de la comunidad de la vida. Como bien lo expresa la Carta de la Tierra, en el Subprincipio 2.a, el ser humano tiene "el derecho a poseer, administrar y utilizar los recursos naturales", pero también tiene "el deber de prevenir daños ambientales". Leonardo Boff, uno de los líderes de la Carta de la Tierra, en un ensayo temático ampliado sobre la misma, ilustra que la Carta representa un importante aporte para una visión holística e integrada de los problemas sociales y ambientales de la humanidad. No considera la ecología como una técnica para manejar recursos naturales escasos, sino como un nuevo paradigma para relacionarse con la naturaleza, en donde "todos los seres conectados entre sî" forman un sistema inmenso y complejo. Ante la comunidad de la vida se deben cultivar dos actitudes fundamentales: respeto y cuidado. El respeto significa, en primer lugar, reconocer al otro y admitir que también existen otros seres más antiguos y, por tanto, merecen existir y cohabitar, y en segundo, percibir su valor intrínseco, que otros seres vivientes tienen un valor independientemente de su utilidad para los seres humanos, conforme lo afirma el Subprincipio 1.a. ${ }^{16}$ Como no podía ser de otro modo, la Carta señala el trato humanitario de los animales individuales como una condición necesaria para el desarrollo sostenible. El Principio 1.a reconoce que todos los seres son interdependientes y que toda forma de vida independientemente de su utilidad tiene valor para los seres humanos. Lo que este principio reconoce es que la sostenibilidad no se refiere únicamente a la condición humana, sino que incluye a todo ser viviente y la mutua interdependencia con todos los seres vivos y sistemas ecológicos. Además de su afirmación general, la Carta de la Tierra también incluye un principio y tres subprincipios enfocados en la protección de los animales, el 15.a, b y c. Sin embargo, para Rick Clugston y John A. Hoyt, los subprincipios del Principio 15 no reflejan un programa coherente para la protección de los animales ya que dejaron de lado la conducción adecuada de pruebas de laboratorio y las condiciones en que se debe criar y sacrificar el ganado, los pollos y los cerdos para consumo humano. Por ende, el Subprincipio 15.a es solo una aseveración de que los animales domesticados deben tratarse en forma humanitaria, sin hacer mención de los contextos específicos. Por otra parte, los Subprincipios $15 . \mathrm{b}$ y 15.c. se refieren a los animales salvajes, afirmando que los métodos utilizados para cazar, atrapar y pescar no deben causar sufrimiento innecesario a los animales, ni ser tan imprecisos como para matar a otros animales accidentalmente. ${ }^{17}$ En cuanto al concepto de integridad ecológica, se refleja a través de todo el documento y específicamente en los Principios 5 a 8 de la misma. El Preámbulo, en su segunda parte, dispone claramente la dependencia del bienestar humano con la preservación de una biosfera saluda-

16 Leonardo Boff, "Respeto y cuidado de la comunidad de la vida mediante el entendimiento, compasión y amor", en La Carta de la Tierra en acción: hacia un mundo sostenible, ed. por Peter Blaze Corcoran, Mirian Vilela y Alide Roerink (Ámsterdam: KIT Publisher BV, 2008), 43-46.

17 Rick Clugston y John A. Hoyt, "La Carta de la Tierra y los animales", en La Carta de la Tierra en acción: hacia un mundo sostenible, ed. por Peter Blaze Corcoran, Mirian Vilela y Alide Roerink (Ámsterdam: KIT Publisher BV, 2008), 155-156. 
ble y con todos sus sistemas ecológicos. Desde la perspectiva de la Carta de la Tierra, la integridad ecológica es necesaria para toda forma de vida, humana y no humana, incluyendo a las generaciones futuras y hasta a las especies aún por existir. La singular contribución de la Carta de la Tierra constituye la integración de las preocupaciones sobre justicia social, bienestar ambiental y animal. Las soluciones del mundo real solo son sostenibles cuando estas tres dimensiones están presentes: el desarrollo es sostenible cuando se brinda justicia a los pobres; se promueve — no se degrada — la integridad ecológica de los ecosistemas de la Tierra; y se respeta el valor intrínseco de todo ser viviente. A este respecto, el Principio 7 hace una exhortación por patrones más sostenibles de producción y de consumo y el Subprincipio 7.d recomienda internalizar los costos ambientales y sociales totales de bienes y servicios en su precio de venta y posibilitar que los consumidores puedan identificar productos que cumplan con las normas sociales y ambientales. En la actualidad, muchos de los efectos nocivos sobre la integridad ecológica no son agregados al costo de producción, por lo cual los consumidores nunca se enteran de las consecuencias ambientales de sus decisiones de inversión y consumo. Hoy en día, se están desarrollando varios sistemas alrededor del mundo en respuesta a este desafío, tales como el Índice de Sostenibilidad Dow Jones (DJSI, por sus siglas en inglés), FTSE4Good Index Series y RepuTex. ${ }^{18}$ La Carta también le ha brindado asistencia a la Sociedad de Vida Silvestre de Australia — una organización ambiental no gubernamental—, a integrar las preocupaciones por la naturaleza silvestre con la sostenibilidad y justicia para las comunidades indígenas. Esta nueva forma de pensar ha hallado expresión, por ejemplo, en el proyecto WildCountry, el que tiene una visión a largo plazo para garantizar la conservación del extraordinario patrimonio natural y la biodiversidad de Australia y está ayudando a realizar el Principio 5 y el Subprincipio 5.b, que alienta a proteger y a restaurar la integridad de los sistemas ecológicos, con especial preocupación por la diversidad biológica y los procesos naturales que sustentan la vida y preservar la herencia natural incluyendo las preocupaciones indígenas dentro de su misión fundamental. ${ }^{19}$

\section{La Declaración Universal de los Derechos de los Animales}

La Declaración Universal de los Derechos de los Animales es una normativa de carácter no vinculante, proclamada solemnemente el 15 octubre de 1978, en la sede de la UNESCO, en París, por la Liga Internacional de los Derechos del Animal. Debemos resaltar que se adoptó en la sede de la UNESCO, vale decir que este organismo internacional prestó su sede, pero

18 RepuTex es la marca registrada de una agencia calificadora pequeńa y totalmente independiente con sede en Melbourne, Australia, que se dedica a la entrega de las Calificaciones de Responsabilidad Social de RepuTex (SRR, por sus siglas en inglés), creada bajo el modelo de los sistemas estándar de calificación crediticia. Esta agencia utiliza la Carta de la Tierra en una cantidad de formas innovadoras.

19 Brendan Mackey, "La integridad ecológica: un compromiso hacia la vida en la Tierra", en La Carta de la Tierra en acción: hacia un mundo sostenible, ed. por Peter Blaze Corcoran, Mirian Vilela y Alide Roerink (Ámsterdam: KIT Publisher BV, 2008), 67-71. 
no fue adoptado por la UNESCO, que es muy diferente, ya que tendría un valor moral más universal. En el Preámbulo considera que todo animal posee derechos, en el artículo 1 que todos los animales nacen iguales ante la vida y que tienen los mismos derechos a la existencia y en el artículo 2 que todo animal tiene derecho al respeto. Además, dispone que todos los animales tienen derecho a la atención, a los cuidados y a la protección del hombre. En el caso que viva tradicionalmente en el entorno humano, tiene derecho a vivir y a crecer al ritmo y en las condiciones de vida y de libertad que sean propias de su especie, y si el hombre lo ha escogido como compañero tiene derecho a que la duración de su vida sea conforme a su longevidad natural. Como deberes para con los animales, el hombre, en tanto que especie animal, no puede atribuirse el derecho de exterminar a los otros animales o de explotarlos violando ese derecho, ni someterlos a malos tratos ni actos crueles. Si es necesaria su muerte, esta debe ser instantánea, indolora y no generadora de angustia. El abandono es un acto cruel y degradante. En la declaración quedó consagrado que todo acto que implique la muerte de un animal sin necesidad es un biocidio y determinó que los derechos del animal deben ser defendidos por la ley, como los derechos del hombre. Ana María Aboglio critica esta Declaración argumentando que, por un lado, no tiene fuerza legal y su incumplimiento no lleva aparejada ningún tipo de responsabilidad. Por el otro, quienes la redactaron desvirtuaron su función ya que conciliaron los intereses de los rubros representativos de las dos explotaciones que generan mayor cantidad de sufrimiento animal: experimentación y comida, dando cabida a la experimentación y a la cría para alimentación. Entonces, no todos nacen iguales. ${ }^{20}$ Sin embargo, esta Declaración ha tenido el mérito de haber sido la primera en construir las bases de un nuevo equilibrio en las relaciones que el hombre mantiene con los animales y a proclamar la igualdad de las especies a la vida, constituyendo el texto más ambicioso que haya aparecido al día de hoy en lo que se refiere al reconocimiento con vocación universal de los derechos de los animales. Justamente, Juan Ramón Blanco Aristín señala que los conceptos éticos contenidos en la Declaración Universal de los Derechos de los Animales se basan en tres factores claves que han surgido con los recientes descubrimientos en la ciencia de la biología moderna, la genética molecular, genética poblacional, ecología, neurofisiología y etología. En el campo de genética molecular se ha mostrado que las especies animales están hechas con las mismas materias encontradas en un código genético universal, tienen un origen común, incluyendo la especie humana. La ecología y la ciencia poblacional han dado a conocer un nivel alto de interdependencia entre especies e individuos que opera dentro de un sistema vivo y extenso, que es la comunidad biológica global. Tanto la neurofisiología ${ }^{21}$ como la etología ${ }^{22}$

20 Ana María Aboglio, "Declaración universal de los derechos animales", Ánima (25 de febrero de 2005), acceso el 21 de abril de 2017, http://www.anima.org.arldeclaracion-universal-de-los-derechos-animales/

21 La neurofisiología es la rama de la fisiología que estudia el sistema nervioso.

22 La etología es la rama de la biología y de la psicología experimental que estudia el comportamiento de los animales en sus medios naturales, en situación de libertad o en condiciones de laboratorio, aunque son más conocidos los estudios de campo. 
han mostrado que los animales sufren de hecho. Todas las especies y todos los individuos, mediante su originalidad, contribuyen a la estabilidad dinámica de la biosfera y cada especie y cada individuo por lo tanto tienen derechos naturales para vivir con dignidad. ${ }^{23}$

La Sociedad Mundial para la Protección Animal (WSPA) elaboró, en el año 2003, la Declaración Universal sobre Bienestar Animal (DUBA), la que fue apoyada por varios Estados y por las organizaciones más importantes de bienestar animal a nivel mundial. ${ }^{24} \mathrm{En}$ su Preámbulo, se establece como principio fundamental que los animales son seres sensibles y que su bienestar debe ser respetado. Luego, en el artículo 1, define el término animal como cualquier mamífero no humano, ave, reptil, anfibio, pez, o invertebrado capaz de sentir miedo o estrés. Asimismo, se especifica que los animales sensibles se refieren a todos los vertebrados y ciertos invertebrados teniendo la capacidad de sentimientos, incluyendo el dolor y el placer con un nivel de conciencia elevado (artículo 3). En el artículo 4 establece la obligación general para todos los Estados miembros de adoptar todas las medidas para prevenir la crueldad hacia los animales, reducir sus sufrimientos y asegurar las cinco necesidades básicas comprendidas dentro del concepto de bienestar animal que implican libertades. Específicamente dispone, en el artículo 5, determinadas directrices a seguir en caso de animales criados para alimentación humana, carga o transporte, en el artículo 6 establece obligaciones para con los animales de compañía y en el artículo 7 , animales para deportes y entretenimiento. Finalmente, en el artículo 8 determina reglas a seguir en el caso de animales vivos para investigación científica. Ninguna de las dos Declaraciones obtuvo aprobación por parte de las Naciones Unidas, sin embargo, las entidades proteccionistas de todo el mundo esperan que la ONU promulgue la Declaración Universal de los Derechos del Animal, que difiere de la Declaración Universal sobre Bienestar Animal al sostener que los animales poseen derechos y no solo libertades.

\section{La Declaración Universal de los Derechos de la Madre Tierra}

En respuesta a la Cumbre de Copenhague ${ }^{25}$, organizada por las Naciones Unidas en diciembre del 2009, calificada por algunos como fracaso, Evo Morales, presidente de Bolivia,

23 Ramón Blanco Aristín, "El espíritu de la Declaración Universal de los Derechos Animales”, Tendencias21 (31 de mayo de 2008), acceso el 21 de abril de 2017, http://www.tendencias21.net/derecho/EL-ESPIRITU-DE-LA-DECLARACION-UNIVERSAL-DE-LAS-DERECHOS-ANIMALES_a45.html

24 Como por ejemplo la Sociedad Humanitaria de los Estados Unidos, la Organización Mundial de Sanidad Animal — OIE_-, la Asociación Veterinaria Mundial —WVA - y la Asociación Mundial de Veterinarios de Pequeños Animales. Entre los Estados que prestaron su apoyo podemos mencionar: Camboya, Fiyi, Nueva Zelandia, Seychelles, Suiza, Inglaterra, Panamá y los Estados miembros de la Unión Europea y, en Argentina, los Colegios de Veterinarios de la Provincia de Buenos Aires y de la Ciudad Autónoma de Buenos Aires.

$25 \mathrm{La} 15^{\circ}$ Conferencia Internacional sobre Cambio Climático se realizó en Dinamarca, desde el 7 al 18 de diciembre de 2009, organizada por la Convención Marco de Naciones Unidas para Cambio Climático, conocida como la Cumbre de Copenhague. 
convocó a la I Conferencia Mundial de los Pueblos sobre el Cambio Climático y los Derechos de la Madre Tierra, que se realizó del 19 al 22 de abril de 2010, en el municipio Tiquipaya, conocido como la "ciudad de las flores", ubicado en el departamento de Cochabamba. El entonces secretario general de las Naciones Unidas, Ban Ki-moon, en su mensaje enviado a los participantes de la Conferencia, enfatizó que "el cambio climático es un tema ético que tiene serias repercusiones en el bienestar de nuestra generación y de las generaciones venideras. Este problema requiere una solución global que tome en cuenta las opiniones y necesidades de todos los que compartimos la Madre Tierra"26 (Ban Ki-moon 2010 — mensaje citado por la CEPAL-). En esa Conferencia Mundial, se aprueba la Declaración Universal de los Derechos de la Madre Tierra, dentro del Acuerdo de los Pueblos, en la que se le reconocen derechos inherentes a la Madre Tierra y a todos seres sin distinción alguna, entre seres orgánicos e inorgánicos, especies, origen, uso para los seres humanos, o cualquier otra condición. En el Preámbulo afirma que, así como los seres humanos tienen derechos, todos los seres de la Madre Tierra también tienen derechos que son específicos a su condición y función dentro de los sistemas en los cuales existen. Los derechos de cada ser están limitados por los derechos de otros seres, y cualquier conflicto entre sus derechos debe resolverse de manera tal que se mantenga la integridad, equilibrio y salud de la Madre Tierra. Dentro de los derechos inherentes a la Madre Tierra enumera el derecho a la vida y a existir; a ser respetada; a la regeneración de su biocapacidad y continuación de sus ciclos y procesos vitales libre de alteraciones humanas; a mantener su identidad e integridad como seres diferenciados, autorregulados e interrelacionados; al agua como fuente de vida; al aire limpio; a la salud integral; a estar libre de la contaminación y polución, de desechos tóxicos y radioactivos; a no ser alterada genéticamente ni modificada en su estructura amenazando su integridad o funcionamiento vital y saludable y a una restauración plena y pronta por las violaciones a los derechos reconocidos en la naturaleza. En el artículo 3 detalla las obligaciones de los seres humanos, quienes son responsables de respetar y vivir en armonía con ella, y en el artículo 4 - definiciones - dentro del término "ser" incluye los ecosistemas, comunidades naturales, especies y todas las otras entidades naturales que existen como parte de la Madre Tierra. Recordamos que para el derecho internacional, la Declaración no tiene fuerza legal, no es vinculante, es una expresión de deseos con fuerza moral. En la misma, a más de promocionar el tema de los derechos de la naturaleza, se planteó la creación de un Tribunal Internacional para sancionar los delitos ambientales.

La Unión Internacional para la Conservación de la Naturaleza, en el Congreso Mundial de la Naturaleza, en Jeju, República de Corea, del 6 al 15 de septiembre de 2012, adoptó la

26 Comisión Económica para América Latina CEPAL, "La ONU busca inclusión y transparencia en debate sobre cambio climático". Comunicado de prensa. CEPAL (22 de abril de 2010), acceso el 21 de abril de 2017, http://www.cepal.org/es/ comunicados/la-onu-busca-inclusion-y-transparencia-en-debate-sobre-cambio-climatico 
Resolución WCC-2012-Res-100-SP "Incorporación de los derechos de la naturaleza como eje articulador de las decisiones de la UICN”. En la misma afirma que cada vez más países están incorporando los derechos de la naturaleza o de la Madre Tierra a sus marcos regulatorios como un nuevo paradigma de sociedades que reconocen a la naturaleza y a sus componentes el derecho a existir y a regenerarse integralmente. Considera que las economías mundiales, especialmente las de los países desarrollados, mantienen patrones de producción y consumo que no consideran los límites del planeta, por todo ello, promueve la elaboración de una Declaración Universal de los Derechos de la Naturaleza, como un primer paso para iniciar una reconciliación entre los seres humanos y la Tierra.

\section{Tribunal Ético Permanente por los Derechos de la Naturaleza y de la Madre Tierra}

En cumplimiento con la Declaración Universal de los Derechos de la Naturaleza, comenzó a sesionar, el 17 de enero del 2014 en Quito-Ecuador, el Primer Tribunal Permanente por los Derechos de la Naturaleza y de la Madre Tierra, presidido por la Dra. Vandana Shiva. El Tribunal, organizado por la Alianza Global por los Derechos de la Naturaleza, promueve una nueva visión para vivir en armonía con la Tierra a través del reconocimiento de los derechos de la naturaleza. Tiene como objetivo promover el respeto universal y la garantía de los derechos establecidos en la Declaración Universal de los Derechos de la Madre Tierra, para lograr una coexistencia armónica entre los seres humanos y el resto de los seres de la naturaleza. Durante la primera sesión, el Tribunal, compuesto por prestigiosos juristas provenientes de diferentes partes del mundo, admitió siete casos puntuales: la contaminación del caso Chevron-Texaco (Ecuador); el derrame de BP Deep Horizon (Estados Unidos); el proyecto de extracción de petróleo Yasuní-ITT (Ecuador); la amenaza contra el Gran Arrecife de Corral debido a la minería de carbón (Australia); la minería metálica a cielo abierto en Cóndor Mirador (Ecuador); los casos de fractura hidráulica (Estados Unidos.), y el caso de la persecución contra los defensores de la naturaleza (Ecuador). Además, se admitieron dos casos de escala global que representaban violaciones sistémicas de los derechos de la Madre Tierra: la amenaza de los organismos genéticamente modificados o transgénicos y el cambio climático. Posteriormente, se han desarrollado cuatro salas especiales alrededor del mundo durante el año 2014: dos relacionadas al caso Yasuní en Ecuador (una presidida por Boaventura de Sousa Santos), otra por el caso Chevron y la industria de combustibles fósiles en San Francisco-Estados Unidos y la cuarta por el Arrecife de Corral en Australia liderada por Brendan Mackey.

Durante los días 5 y 6 de diciembre, el Tribunal Internacional por los Derechos de la Naturaleza se reunió en pleno, por segunda vez, en la ciudad de Lima, Perú, para tratar doce casos paradigmáticos sobre violaciones de los derechos de la naturaleza. En esta segunda edición, los doce casos que se trataron fueron los del Yasuní-ITT, Chevron-Texaco y el proyecto minero Cóndor Mirador en Ecuador; el de British Petroleum en el Golfo de México; el del 
gran arrecife de coral en Australia; la represión a los defensores de la Madre Tierra en Bagua, la mina de Conga-Cajamarca y las Cuencas-PUINAMUDT contaminadas por la explotación petrolera en Perú; el de la central hidroeléctrica Belo Monte en Brasil; y, finalmente, los casos globales sobre la fractura hidráulica y el mecanismo de Reducción de Emisiones por Deforestación y Degradación de Bosques (REDD+). Además, se puso especial énfasis en el caso global sobre el cambio climático y las falsas soluciones que se proponen para enfrentarlo. El Tribunal tiene la jurisdicción de investigar y dictaminar cualquier violación seria de los derechos, o infracción de responsabilidades establecidas en la Declaración Universal de los Derechos de la Madre Tierra, sean estas cometidas por organizaciones internacionales, Estados, personas jurídicas privadas o públicas o individuos. En primer lugar, debe escuchar los casos de presuntas violaciones a los derechos de la naturaleza inscriptos en la Declaración Universal por los Derechos de la Madre Tierra, con el fin de determinar si ha habido o no una violación. En caso afirmativo, debe aceptar el caso, estudiar las causas, recibir las evidencias, deslindar responsabilidades y emitir sentencias fijando las medidas que se deben tomar para prevenir que se repitan esas violaciones, así como para restaurar integralmente los daños a la naturaleza y a las comunidades afectadas. Posteriormente, debe publicar su trabajo, sentencias, fallos y opiniones consultivas. También puede efectuar recomendaciones a las partes involucradas participando como mediador acerca de los procedimientos de justicia restaurativa y debe emitir las opiniones consultivas que se le soliciten. Si bien es un gran avance en pos de la naturaleza, los ecosistemas y todos los seres vivos, debemos recordar que para el derecho internacional sus sentencias no son coercitivas, carecen de jurisdicción compulsiva y de vinculación jurídica, son correctivos morales, por lo cual su incumplimiento no genera responsabilidad internacional en términos jurídicos. Sin embargo, su fuerza reside en el reconocimiento de los derechos de la naturaleza y en generar conciencia. En síntesis, los casos presentados fueron los siguientes:

a) Caso Yasuní contra Ecuador: el Parque Nacional Yasuní es el lugar con más biodiversidad del hemisferio oriental, tiene una extensión de 982000 hectáreas de bosque amazónico, con una alta biodiversidad que excede en árboles, por ejemplo, al número total de Estados Unidos y Canadá. Es también el hogar de dos pueblos indígenas en aislamiento, los Tagaeri y los Taromenane. Ecuador, el 15 de agosto del 2013 decidió explotar el petróleo por lo cual, el mismo año se conformó el Colectivo Yasunidos, quienes recogieron más de 750 mil firmas para llamar a una consulta nacional sobre la explotación, sin embargo, no se dio curso a su pedido. El Tribunal aceptó el caso de la explotación del Yasuní en enero del 2014 como una potencial violación a los derechos de la naturaleza, y el 15 de agosto del 2015 se volvió a reunir un Tribunal-Sala especial donde condenaron las violaciones a los derechos de la naturaleza en dicha área, a las de los dos pueblos indígenas y conminó al Gobierno ecuatoriano respetar y garantizar los derechos de la naturaleza. En la sentencia, el Tribunal se pronuncia, "desde la piel de los delfines rosados, de los monos aulladores, desde la piel de los pueblos libres en 
aislamiento voluntario, desde los zapatos de los Yasunidos, ${ }^{27}$ todos, amenazados por la explotación petrolera y la destrucción de la vida del Yasuní, se pronuncia desde quienes defienden la vida y la democracia”. ${ }^{28}$ Además, considera fundamental universalizar los derechos de la naturaleza, así como ha sucedido con los derechos humanos.

b) Caso Chevron-Texaco contra Ecuador: el 5 de febrero de 1964 el Gobierno de Ecuador firmó la concesión con la compañía Gulf Texaco Consortium para la explotación petrolera en la zona norte de la Amazonía ecuatoriana. Durante su operación, hasta 1992, la compañía tuvo impactos tan devastadores en el ambiente, y por ende sobre la población del área, que deforestó más de 2 millones de hectáreas, derramó más de 650 mil barriles de petróleo y arrojó millones de litros de agua de formación y metales pesados a las fuentes de agua del lugar, afectando a poblaciones indígenas y mestizas de la zona. ${ }^{29} \mathrm{El} 7$ de mayo del 2003, los afectados por las operaciones de Texaco iniciaron las acciones legales contra la petrolera en la Corte Superior de Justicia de Sucumbíos, y luego de 10 ańos de litigio, el 12 de noviembre de 2012, los demandantes obtuvieron, de la Corte Nacional, la ratificación de la sentencia contra Chevron Corporation (antes Texaco) por todos los dańos ambientales causados. Sin embargo, a pesar de estas victorias ante los tribunales competentes, la compañía se niega a reconocer la sentencia en su contra. Debido a que Chevron ya fue condenada por este enorme daño ambiental, los demandantes no buscan que este Tribunal Ético se manifieste nuevamente sobre el tema, sino que solicitan que se pronuncie y condene a la Compañía por el daño que causa al negarse a cumplir la condena y por perseguir judicialmente a sus víctimas. Los daños persisten. ${ }^{30}$

c) Caso British Petroleum contra Estados Unidos: el 20 de abril del 2010 hubo una explosión del "Deepwater Horizon" que la empresa British Petroleum operaba con la compañía suiza Transocean, causando un derrame de aproximadamente 5 millones de barriles de petróleo en el Golfo de México y la muerte de 11 trabajadores. El petróleo siguió fluyendo en el océano, derramando entre 12 y 19 mil barriles diarios. El derrame paró en julio de ese año,

27 Yasunidos es un colectivo de colectivos que surgió de una unión de diversas organizaciones de ambientalistas, artistas, ciclistas urbanos, entre otros. Nació como una respuesta de alguna forma desesperada al anuncio del presidente Correa de poner fin al proyecto Yasuní-ITT, un plan ambiental al que muchos jóvenes ecuatorianos habían apostado.

28 "El veredicto del Tribunal Ético por los Derechos de la Naturaleza, caso Yasuní", Global Alliance for the Rights of Nature (15 de agosto de 2014), acceso el 21 de abril de 2017, http://therightsofnature.org/veredicto-del-tribunal-caso-yasunil

29 El litigio contra la compañía Texaco se planteó inicialmente en la ciudad de New York, sede global de Texaco, el día 3 de noviembre de 1993, y después de nueve años de batalla legal en los Estados Unidos, el 16 de agosto de 2002, la Corte de Apelaciones del Distrito Sur de New York resolvió, frente a la demanda presentada por los pobladores ecuatorianos, que los demandantes tenían derecho a un juicio, por lo que dispuso que Texaco debía someterse a la justicia ecuatoriana y cumplir con cualquiera sentencia en su contra, argumentando que era un foro más adecuado para este caso en razón que en Ecuador se encontraban los documentos, testigos y demás evidencia y que la sentencia que dictara la justicia ecuatoriana sería ejecutable ante la justicia norteamericana.

30 Julio Prieto, "Juicio contra Chevron en el Ecuador" (17 de enero 2014), acceso el 5 de mayo de 2017, http://therightsofnature.org/wp-content/uploads/Memorial-Caso-ChevronSP.pdf 
pero los daños al ecosistema marino persisten y persistirán por mucho tiempo más. Todavía no se resolvió, el Tribunal debe escuchar más evidencia y resolver el caso con una sentencia.

d) Caso Fractura Hidráulica ${ }^{31}$ contra Estados Unidos, Bolivia y Argentina: el caso fue presentado en el Tribunal en Quito y aceptado como una posible violación a los derechos de la naturaleza y a las poblaciones. El Tribunal pidió asimismo que se celebraran consultas con científicos y testimonios de las comunidades afectadas directamente por este desarrollo para recabar más información sobre el alcance y la magnitud de los dańos causados por las fracturas hidráulicas. Estos documentos se transmitirán además al secretario general de las Naciones Unidas para su conocimiento en el marco del programa Armonía con la Naturaleza. ${ }^{32}$

e) Caso Cóndor Mirador contra Ecuador: el 5 de marzo del 2012, el Estado ecuatoriano firmó el primer contrato de minería metálica a gran escala con la empresa china Ecuacorriente S. A, permitiendo así la extracción de cobre en uno de los lugares más biodiversos de ese país como es la Cordillera del Cóndor. A pesar de haber sido presentada una demanda por parte de la sociedad civil organizada por la violación de los derechos de la naturaleza demostrando la extinción de especies y afectación a las fuentes de agua, la empresa Ecuacorriente ganó la contienda dejando a la naturaleza y a los pobladores en la indefensión. El Tribunal solicitó a los demandantes que presentaran evidencias e información adicional del caso.

f) Caso Mina de Conga-Cajamarca contra Perú: en Perú, cuatro lagunas andinas en las montañas de Cajamarca se ven amenazadas por la Mina de Conga (proyecto entre Newmont Mining, Buenaventura de Perú y la Corporación Financiera Internacional) que busca iniciar un proyecto de mina. Los Guardianes de las Lagunas han promovido grandes movilizaciones contra la destrucción de sus lagunas, y el Gobierno ha respondido con la criminalización de cientos de personas, golpes y arrestos. Cinco personas han muerto y no se encuentra todavía el responsable. El Tribunal resolvió admitir el caso y decidió nombrar un comité especial para visitar la zona y reunir información sobre la situación.

g) Caso Cambio climático y falsas soluciones: los efectos del cambio climático en el planeta incluyen aumentos en el nivel del mar, acidificación de los océanos, pérdida de biodiversidad, efectos en los ciclos de agua, desertificación, incendios, aumentos de los fenómenos climáticos, entre otros. El Tribunal en Quito aceptó el caso del cambio climático como una evidente violación a los derechos de la naturaleza, y en Lima escuchó evidencia adicional al caso relacionado con los impactos a la Madre Tierra, las falsas soluciones y los responsables

31 La fractura hidráulica es una técnica de explotación de petróleo y gasífera a través de la inyección de altas presiones de agua, arena y productos químicos en las formaciones rocosas ricas en hidrocarburos.

32 Tom Goldtooth, "Hydraulic Fracking Case Verdict, International Rights of Nature Tribunal, Lima, Peru, December 2014”, Global Alliance for the Rights of Nature (December 6, 2014), acceso el 22 de abril de 2017, http://therightsofnature.org/fracking-case-verdictl 
de estos delitos contra la naturaleza. Asimismo, consideró necesario expresar a las Naciones Unidas su preocupación por un escenario que contempla el uso de energías de alto riesgo.

h) Caso Gran Arrecife de Coral contra Australia: el Gran Arrecife de Coral es el sistema de corales más grande del mundo, conformado por organismos vivos, que puede ser vista desde el espacio. ${ }^{33}$ Michelle Maloney, miembro de la Australian Earth Laws Alliance (AELA) dio testimonio utilizando un marco innovador al hablar en nombre del Gran Arrecife de Coral, como miembro de la comunidad de la Tierra y como una "entidad legal". Reconoció a los Guardianes Tradicionales de la tierra y del mar que comprende lo que ahora se llama el Gran Arrecife de Coral, y, a la vez, admitió que no era uno de ellos, sino solo un miembro interesado de la comunidad humana de Australia. Su declaración incluyó lo siguiente:

Sin el Arrecife, no hay hogar, no hay un lugar acogedor para jugar, no hay donde esconderse de los depredadores, ni lugar para depositar sus huevos. Si el Arrecife desaparece, también lo harán los millones de especies de vida que llaman al Arrecife su hogar. Si el Arrecife desaparece, no hay ningún otro lugar para estas comunidades de vida [...]. Durante miles de años la gente nos visitaba en el Arrecife: entraba y salía con sus barquitos, pescaba con mucho respeto y luego volvía a su casa. Pero ahora los barcos se han vuelto más grandes. Y hay muchos más de ellos. Observamos la costa con miedo cuando se producen grandes lluvias, ya que los ríos se llenan de sedimentos y de basura arrojada por la gente de la tierra y los desperdicios y la basura salen de los ríos a nuestro Arrecife. Así que, en conclusión, ¿cómo se podría sentir el Arrecife? Me imagino que siente de la misma manera que las personas que lo quieren y que se preocupan por él. Tenemos miedo. Tenemos miedo porque algo valioso, irremplazable y antiguo morirá. ${ }^{34}$

Al final de la audiencia, cada uno de los jueces del Tribunal emitió declaraciones sobre el estado de los casos sometidos a consideración. Cormac Cullinan, designado como miembro del Tribunal para el Caso Arrecife de Coral, expresó su firme convicción de que los derechos de la naturaleza fueron y seguirán siendo violentados en ese caso (el de Gran Barrera de Coral - GBR), en especial la Declaración Universal de los Derechos de la Madre Tierra. La evidencia fue concluyente con respecto a la violación de los siguientes derechos: el derecho a estar libre de contaminación y de los residuos tóxicos o radiactivos; el derecho a la salud integral, por ejemplo, la salud del arrecife, así como la salud de los peces y otros seres; y el derecho de cada ser para el bienestar, de la destrucción del ecosistema del Arrecife, que es potencialmente la

33 Tiene $2300 \mathrm{~km}$ y cuenta con más de 3000 sistemas de corales individuales, además de ser el soporte de vida de cientos de especies de peces, tiburones, rayas, ballenas, delfines y moluscos. Es considerado patrimonio mundial por la UNESCO, institución que en junio del 2011 emitió una advertencia al Gobierno australiano por la amenaza al Gran Arrecife de Coral debido a la expansión de puertos, especialmente para la exportación de carbón, el dragado, los sedimentos agrícolas y los desarrollos industriales cercanos al Arrecife.

34 Michelle Maloney, "Finally Being Heard: The Great Barrier Reef and the International Rights of Nature Tribunal", Griffith Journal of Law \& Human Dignity, 3 (2015). ISSN: 2203-3114. 
violación del derecho a continuar los ciclos vitales y los procesos, libre de trastornos humanos. En consecuencia, llegó a la conclusión de que el caso debía ser admitido para su examen por el Tribunal Permanente. ${ }^{35}$ En virtud del dictamen de Cullinan, el caso fue aceptado por el Tribunal y anunció que haría sus conclusiones y recomendaciones en la segunda audiencia, en diciembre de 2014, en Lima, Perú. Finalmente, resolvió que las autoridades de Australia debían controlar eficazmente las actividades humanas en la zona, prohibir el paso a través de zonas sensibles del arrecife, restaurarlo completamente, cumplir plenamente las recomendaciones de la UNESCO, reducir la contaminación marina derivada de la agricultura, los residuos industriales, el desarrollo urbano y abstenerse de construir más y ampliar los puertos existentes. Además, condenó al Gobierno de Australia por las violaciones de los derechos del Arrecife para mantener sus ciclos vitales y la capacidad para cumplir su potencial natural. El turismo debe ser sensible a la protección y a la salud del mismo. ${ }^{36}$

i) Caso Bagua contra Perú: se refiere a la aplicación de diez decretos legislativos y leyes en el marco del Tratado de Libre Comercio entre Perú y Estados Unidos. Los pueblos indígenas amazónicos comenzaron con protestas, en mayo del 2008, en contra de este paquete de decretos - muy direccionados a favor de las empresas transnacionales petroleras y mineras-. Estas protestas fueron confrontadas por la fuerza gubernamental. Cinco años más tarde, 52 líderes indígenas tienen juicios en su contra.

j) Caso Cuencas-PUINAMUDT contra Perú: las cuencas de los ríos Pastaza, Corrientes y Río Tigre en Perú han sido contaminadas por décadas debido a la explotación petrolera en la Amazonía peruana. Entre las compañías responsables se encuentran Occidental Petroleum y Pluspetrol. Durante el último año, el Ministerio de Ambiente de Perú ha declarado a estos ríos en "estado de emergencia", pero muy poco se ha hecho para remediar esta situación. Las comunidades indígenas, bajo las federaciones FECONACO y FEDIQUEP, se han movilizado a través de la plataforma PUINAMUDT para protestar y exigir que se remedie el daño.

k) Caso Belo Monte contra Brasil: la central hidroeléctrica Belo Monte, construida por la compañía Norte Energia Consortium en el río Xingu, en el Estado de Pará-Brasil, tiene una capacidad planeada de $11000 \mathrm{MW}$, siendo así la segunda mayor hidroeléctrica brasileńa, y la tercera más grande del mundo. Esta represa devastará un área de más de $516 \mathrm{~km}^{2}$ de la Amazonía brasilera y causará el desplazamiento de 20000 personas, afectando los modos de vida de decenas de familias y comunidades indígenas. La cuenca de Xingú es altamente biodiversa y es el hogar de 25000 indígenas de 24 grupos étnicos como los kayapó, arara, juruna, arawe-

35 "Cormac Cullinan Judges Ruling on Great Barrier Reef Case. Rights of Nature Tribunal - Quito Ecuador", Global Alliance for the Rights of Nature (January 2014), acceso el 30 de abril de 2017, http://therightsofnature.org/cormac-cullinangreat-barrier-reef-casel

36 "Great Barrier Reef Verdict - Lima. International Rights of Nature Tribunal, Lima - Perú", Global Alliance for the Rights of Nature (December 2014), acceso el 2 de mayo de 2017, http://therightsofnature.org/great-barrier-reef-verdict-limal 
té, xikrin, asurini y parakanã. El Tribunal aceptó el caso y se celebrará una sesión especial en Brasil para su conocimiento.

1) Caso REDD contra Estados Unidos, Kenia y Costa Rica: REDD —Reducción de Emisiones por Deforestación y Degradación de los bosques- es una iniciativa global que crea un valor financiero al carbono almacenado en los bosques nativos y plantaciones de árboles, suelos y agricultura, incluyendo al plancton y a las algas de los océanos. Los pueblos indígenas, los habitantes de los bosques, los pequeños agricultores y los campesinos y campesinas ven a REDD como una falsa solución para mitigar el cambio climático, que ha resultado en el acaparamiento de tierras, desalojos y violaciones a los derechos humanos y lo describen como el pilar de la Economía Verde y de la Financiación de la Naturaleza. El Tribunal escuchará testimonios relacionados a REDD y otros regímenes del comercio de carbono.

El Tribunal Internacional por los Derechos de la Naturaleza, organizado por la Alianza Global, en asociación con End Ecocide on Earth, NatureRights y Attac France, ${ }^{37}$ se reunió por tercera vez en la Maison des Métallos, París, simultáneamente con la Convención Marco de las Naciones Unidas sobre el Cambio Climático (COP 21). Sus conclusiones fueron fuertes y claras, las evidencias presentadas establecieron sin lugar a dudas que los derechos humanos y los derechos de la naturaleza son inseparables y que ambos están siendo sistemáticamente violados. Entre las diversas recomendaciones que efectuó, se encuentra la de modificar el Estatuto de Roma para permitir que los autores del delito de ecocidio sean procesados ante la Corte Penal Internacional, apoyó firmemente el mantenimiento de los combustibles fósiles en el suelo, vale decir mantener el petróleo en el suelo, el gas debajo de la hierba y las arenas de alquitrán en la tierra. Es de destacar que elogió el dictado de ordenanzas locales y otros documentos que reconocían los derechos de la naturaleza en los Estados Unidos como medios efectivos para detener la destrucción y recomendó que se siguieran estas iniciativas en otros lugares del mundo. Con una fuerte crítica, señaló que la única mención en los textos oficiales de la COP21 sobre la integridad de los ecosistemas, la Madre Tierra y los pueblos indígenas —en el párrafo 10 - estaba en peligro de ser eliminada. Finalmente, condenó la violencia producida por el terrorismo y efectuó un llamamiento a todas las comunidades y organizaciones que comparten su visión a instituir más tribunales regionales bajo la égida del Tribunal Internacional. Los casos presentados en el Tercer Tribunal Internacional por los Derechos de la Naturaleza en París ${ }^{38}$ fueron:

37 El Tribunal fue integrado por prestigiosos juristas, entre los que se destacan Cormac Cullinan, Tom BK Goldtooth, Alberto Acosta, Osprey Orielle Lake, Terisa Turner, Felicio Pontes y Damien Short. El Tribunal abrió y cerró con emotivas evocaciones a la Madre Tierra por las comunidades indígenas, quienes presentaron testimonios y reclamos en temas como cambio climático, fracking e industrias extractivas.

38 "Tribunal Offers Earth-Driven, Not Market-Driven, Solutions to Climate Change", Global Alliance for the Rights of Nature (Wednesday, December 9th, 2015), acceso el 13 de junio de 2017, http://therightsofnature.org/ron-events/tribunal-offers-earth-driven-not-market-driven-solutions-to-climate-changel\#_ftn1 e "International Rights for Nature Tribunal 
a) Cambio climático: el caso fue presentado por el exembajador boliviano ante las Naciones Unidas, Pablo Solón, y el Tribunal determinó que la evidencia era incuestionable, que la geoingeniería, la energía nuclear, la agricultura industrial y "climáticamente inteligente", los biocombustibles y la explotación acelerada de combustibles fósiles estaban violando sistemáticamente los derechos de la naturaleza.

b) Comercialización de la naturaleza: el caso de la financiación de la naturaleza, presentado por Ivonne Yanez, amplió el caso tratado en la anterior sesión del Tribunal que antes solo trataba el REDD + (Reducción de Emisiones por Deforestación y Degradación Forestal). Ese organismo tomó nota del surgimiento de muchos más casos de mercantilización y comercialización de la naturaleza, por ejemplo, compensaciones de biodiversidad, de carbono, los llamados mecanismos de desarrollo limpio y la denominada agricultura inteligente, y decidió mantener el caso abierto.

c) Defensores de la Madre Tierra: en el Tribunal se escucharon dos casos de los Defensores de la Madre Tierra: el primero, la criminalización de Defensores en Ecuador, y el segundo, la persecución de los Defensores que protestaron contra la contaminación en Houston, Texas, por combustibles fósiles y la contaminación química. Exigió la restitución de los derechos humanos, especialmente de la libertad y la reapertura de las instituciones clausuradas en Ecuador. Cerró el caso de Ecuador, pero mantuvo abierto el de Texas para reunir nuevas pruebas.

d) Fracking: el Tribunal ya había celebrado audiencias sobre fracking global en sus anteriores sesiones en Quito y Lima. Sin embargo, escuchó testimonios sobre el daño causado en Argentina. Los testigos dieron testimonio sobre cómo, en Estados Unidos, el fracking está "rompiendo los huesos de la Madre Tierra", y varios expertos aportaron pruebas adicionales. ${ }^{39}$ Después de escuchar las nuevas pruebas presentadas en París, los jueces decidieron cerrar este caso, pero reconocieron que es una amenaza continua que debe seguir siendo examinada por los tribunales regionales.

e) Megarrepresas en Brasil: Gert Peter Bruch y Christian Poirier (Amazon Watch) presentaron el caso de las megarrepresas en Brasil, con poderosos testimonios. La cuenca del Xingu es una de las áreas más ricas en diversidad biológica y cultural, donde viven 25000 indígenas de 40 grupos étnicos. Las megarrepresas brasileñas están desviando hasta el 80 \% del río Xingu, principal afluente del Amazonas, destruyendo ecosistemas y forzando el desplazamiento de hasta 40000 personas de comunidades indígenas. Además era solo el comienzo de una ola

- Paris, December 4-5", Global Alliance for the Rights of Nature, acceso el: 30 de mayo de 2017, http://therightsofnature. org/rights-of-nature-tribunal-paris/

39 Por ejemplo, Kandi Mosset fue un testigo y residente de Fort Berthold en Oklahoma que dio testimonio de los efectos devastadores de los campamentos de trabajadores mineros que habían rodeado a su comunidad, ocasionando violencia sexual y acoso contra los nińos y las mujeres. 
de entre 60 a 70 proyectos de megarrepresas que se están planificando que podrían conducir a más de $5000 \mathrm{~km}^{2}$ de desforestación de bosques tropicales, y el Estado brasileño había ignorado las conclusiones de la Comisión Interamericana de Derechos Humanos sobre las violaciones al artículo 169 de la OIT (derecho de las comunidades indígenas a una consulta previa e informada), permitiendo el asesinato del modo de vida de las comunidades indígenas. El Tribunal condenó la construcción de las megarrepresas de Belo Monte y Tapajos, las demás planeadas y decidió dejar el caso abierto para escuchar pruebas adicionales en un Tribunal Regional en Brasil.

f) Ecocidios: el Tribunal reconsideró dos casos que había escuchado con anterioridad, con el objetivo de determinar si, además de ser violaciones de la Declaración, también había pruebas que eran ejemplos del delito internacional de ecocidio. ${ }^{40}$ Polly Higgins planteó una definición de ecocidio ante las Naciones Unidas, considerando que "el Ecocidio es el daño grave, la destrucción o la pérdida de ecosistemas de un territorio determinado, ya sea por la acción humana o por otras causas, de tal magnitud que el disfrute pacífico de ese territorio por sus habitantes se ha visto o se verá severamente disminuido". ${ }^{41}$ En los años ochenta, la Comisión de Derecho Internacional de la ONU incluyó este delito dentro del Proyecto de Código de Crímenes contra la Paz y la Seguridad de la Humanidad ("El Código"). Sin embargo, en 1996, el ecocidio fue eliminado del borrador debido a la presión de países como Estados Unidos, el Reino Unido y los Países Bajos, y fue ese documento el que se convirtió en el Estatuto de Roma de la Corte Penal Internacional, adoptado en 1998 y que entró en vigor el 1 de julio de 2002. No obstante, muchos países han reconocido el delito de ecocidio en su legislación penal nacional, a saber: Vietnam en 1990, Rusia en 1996, Kazajistán y Kirguizistán en 1997, Tayikistán en 1998, Georgia y Bielorrusia en 1999, Ucrania en 2001, Moldavia en 2002 y Armenia en 2003. ${ }^{42}$ Actualmente, Polly Higgins está impulsando una campańa mundial en favor de la declaración del ecocidio como crimen contra la paz para 2020, y los promotores de la campaña End Ecocide in Europe (Acabemos con el ecocidio en Europa) trataron de que la Unión Europea aprobara una directiva que declarase la destrucción de ecosistemas como crímenes contra la humanidad y contra la paz, y aunque no obtuvieron las suficientes firmas, no descartan presentar el tema en forma de petición ordinaria al Parlamento Europeo. ${ }^{43}$ Si nos

40 Dicho término se utilizó por primera vez en 1970, en la Conferencia legislativa sobre la guerra y la responsabilidad nacional en Washington, donde el Prof. Arthur W. Galston propuso un nuevo acuerdo internacional para prohibir el ecocidio basado en su investigación en la Universidad de Yale que condujo a la invención del agente naranja utilizado en la Guerra de Vietnam, fabricado por Monsanto. En 1972, en la Conferencia de Estocolmo de las Naciones Unidas sobre el Medio Ambiente Humano, el Sr. Olof Palme, primer ministro de Suecia, habló explícitamente en su discurso de apertura de la guerra de Vietnam como un ecocidio.

41 Polly Higgins, Damien Short y Nigel South, "Protecting the planet: a proposal for a law of ecocide", Crime Law Soc Change 59 (2013), ISSN 0925-4994.

42 Para ampliar sobre el tema ver: Anja Gauger et al., The Ecocide Project. Ecocide is the missing 5th Crime Against Peace (London: Human Rights Consortium, School of Advanced Study, University of London, 2013), 7-12.

43 Pau Ruiz, "El quinto crimen contra la paz", ecoavant.com (31 de enero de 2014), acceso el 2 de junio de 2017, http://www. 
detenemos brevemente en la importancia de tipificar el crimen de ecocidio, podemos afirmar que prohibirá el daño masivo y la destrucción de la Tierra mediante la creación de un deber jurídico de cuidado y establecerá medidas para evitar tanto el ecocidio causado por el hombre como las catástrofes naturales o una devastación cultural (la pérdida del modo de vida de una comunidad - ecocidio cultural—). Al tratarse de una ley penal, su enjuiciamiento es un deber principal del Estado, y si no quiere o no lo puede llevar a cabo, los individuos podrán buscar retribución a través de la Corte Penal Internacional. Volviendo a los casos presentados ante el Tercer Tribunal Internacional por los Derechos de la Naturaleza, el mismo volvió a examinar el caso Yasuní (que involucra la explotación petrolera propuesta en un parque nacional en la Amazonía ecuatoriana) y el caso Chevron (que implica la responsabilidad de rectificar los enormes daños a la Amazonía causados por Texaco / Chevron) desde la perspectiva del ecocidio. El Tribunal determinó que el caso Chevron era uno de los peores casos de ecocidio perpetrado en la Amazonía y que la justicia restaurativa debía ser aplicada. Señaló que las personas naturales, como los directores de Chevron y los funcionarios corruptos del Gobierno, también podrían ser penalmente responsables en su capacidad personal. Con respecto a Yasuní, decidió que sería apropiado emitir una directiva que prohíba la explotación futura del Yasuní como medida para prevenir el ecocidio.

c) Organismos genéticamente modificados: la Dra. Vandana Shiva dirigió la presentación de este caso, el Tribunal escuchó los testimonios de expertos quienes expusieron el daño que los organismos genéticamente modificados - OGM- y que los pesticidas asociados les causaban a los consumidores, a los animales y al suelo, y se dieron evidencias de cómo el pesticida RoundUp de Monsanto se había convertido en uno de los mayores escándalos de salud en el planeta. El Tribunal decidió mantener el caso abierto para escuchar pruebas adicionales.

Entre el 15 y el 16 de octubre de 2016, la multinacional Monsanto fue sometida a un tribunal ético de opinión integrado por cinco jueces, entre ellos, la argentina Eleonora Lamm, subdirectora de Derechos Humanos de la Suprema Corte de Mendoza. Para ello, se utilizaron los mismos procedimientos que utiliza la Corte Penal Internacional de La Haya, pero la compañía se negó a participar. El tribunal encontró a la empresa culpable del delito de ecocidio, de crímenes de guerra, de violaciones de los derechos a un ambiente sano y equilibrado, a la salud, a la alimentación, de quebrantar la libertad científica e instó a las Naciones Unidas a incorporarlo como delito penal al Estatuto de Roma que rige a la Corte Penal Internacional de La Haya. Después de analizar el testimonio de más de 30 personas sobre la contaminación producida por la canola transgénica en Australia y Canadá, la imposibilidad de obtener un buen rendimiento en los cultivos de algodón modificado genéticamente, los intentos de Monsanto de monopolizar el mercado de semillas en la India, la fumigación aérea de glifosato

ecoavant.com/es/notices/2014/01/el-quinto-crimen-contra-la-paz-1926.php\# 
y la contaminación con glifosato de las fuentes de agua en la Argentina, la conclusión fue tajante. Si bien las conclusiones arribadas no tienen un efecto vinculante, ponen en evidencia la problemática, generan una presión social muy relevante, y la prueba que reúnen puede servir para los procesos penales que la sociedad civil impulse en sus jurisdicciones. ${ }^{44}$

h) Nuevos casos aceptados para posteriores audiencias en otras sesiones del Tribunal: se presentaron varios nuevos casos como posibles violaciones de los derechos de la naturaleza que justificaban que el Tribunal los oyera en el futuro. Todos fueron aceptados para su posterior examen y dio instrucciones sobre cómo se debían desarrollar los siguientes casos: 1) el caso Corralejas referido al asesinato cruel de toros en Colombia y el Tribunal determinó que había pruebas claras de tortura y crueldad a los animales; 2) el caso de la comunidad de Rosia Montana en Rumania que ha sido amenazado por la minería de oro; 3) el agotamiento de la vida marina; 4) el caso Shell en Nigeria y 5) el caso de las arenas bituminosas de Canadá. Las arenas bituminosas de Athabasca son un gran depósito de bitumen rico en crudo, situado en el norte de Alberta, Canadá. ${ }^{45}$ Grupos ambientalistas señalan que las arenas se encuentran debajo de más de $140800 \mathrm{~km}^{2}$ de bosques y humedales y que no solamente grandes áreas pueden ser desforestadas, sino contaminadas con aguas residuales tóxicas y que el crudo de arenas bituminosas emite más gases contaminantes. ${ }^{46} \mathrm{El}$ Tribunal observó que existían pruebas de que este podía ser uno de los casos más peligrosos de ecocidio en el planeta.

Con posterioridad al Tercer Tribunal Internacional por los Derechos de la Naturaleza, un panel de jueces se reunió el 30 de abril de 2016, en Antioquía, para considerar la contaminación del ecosistema del Delta de la Bahía de San Francisco, ${ }^{47}$ el cual sufre un estado de perpetua sequía causada por el hombre. Se estima que el 95 por ciento del hábitat natural del

44 Juan Parrilla, "Monsanto, hallado culpable por dańos a la salud y el ambiente, crímenes de guerra y ecocidio", Infobae (18 de abril de 2017), sección Sociedad, acceso el 2 de junio de 2017, http://www.infobae.com/sociedad/2017/04/18/monsanto-hallado-culpable-por-danos-a-la-salud-y-el-ambiente-crimenes-de-guerra-y-ecocidiol

45 El depósito de Athabasca es la única gran reserva de arenas de petróleo en el mundo que es adecuada para la minería a cielo abierto a gran escala, aunque la mayor parte de él solo puede producirse usando la tecnología más recientemente desarrollada y grandes cantidades de agua y energía. Sus reservas de petróleo son las terceras a nivel mundial, después de las de Arabia Saudita y Venezuela. El producto obtenido es betún o bitumen, rico en crudo, que debe ser separado de las arenas de alquitrán, o como el Gobierno canadiense prefiere llamarlas, arenas de petróleo. A diferencia del crudo que se extrae de pozos petroleros, el bitumen requiere una operación de minería a cielo abierto, en la que grandes extensiones son lavadas con una mezcla de agua y sustancias químicas para separar el betún de una mezcla de arena y arcilla. Grandes cantidades de agua se requieren para extraer y procesar el bitumen en comparación con el petróleo convencional, por lo que extraer el betún y procesarlo es una operación altamente intensiva desde el punto de vista energético.

46 "El polémico crudo de Canadá que muy pocos quieren", BBC Mundo, 29 de noviembre de 2011, acceso el 23 de abril de 2017, http://www.bbc.com/mundo/noticias/2011/11/111129_petroleo_alquitran_canada_am.shtml

47 La construcción de los túneles es un proyecto multimillonario que reduce significativamente los flujos necesarios para las vías fluviales y los peces de Delta. Aceleró la extinción de una multitud de especies de peces, incluyendo el salmón Chinook del invierno del río Sacramento, el Delta Smelt, el esturión verde, el blanco, la perca, la lubina rayada y las especies marinas que dependen de esos peces como alimento, como la ballena asesina. Los túneles también exportan agua del río Trinity, el afluente más grande del río Klamath, poniendo en peligro las poblaciones de salmón, trucha y lamprea que juegan un papel importante en la cultura y el suministro de alimentos de las tribus Yurok, Hoopa Valley y Karuk. 
Delta pereció y entre 2,1 millones y 6,9 millones de litros de agua se exportan cada año. El Tribunal escuchó los tristes testimonios de algunos residentes del Delta ${ }^{48}$ y expertos e identificó nuevas estrategias para proteger los derechos humanos y la naturaleza. Docenas de leyes estadounidenses e internacionales han comenzado a reconocer los derechos y la legitimación procesal de los ecosistemas y las especies como un nuevo marco para la protección del ambiente, incluso para el asediado Delta, todos inspirados en la Declaración Universal de los Derechos de la Madre Tierra.

Finalmente, el 7 y 8 de noviembre de 2017, se reunió en el LVR-Landes Museum situado en Bonn, Alemania, el Cuarto Tribunal Internacional de Derechos de la Naturaleza, ${ }^{49}$ coincidiendo, en lugar y fecha, con la Cumbre de las Partes Naciones Unidas por el Cambio Climático (COP23). El Tribunal consideró los siguientes casos: ${ }^{50}$

a) Cambio climático y las falsas soluciones energéticas: revisa cómo la fractura hidráulica, la energía nuclear y la consolidación de la industria de los combustibles fósiles en Estados Unidos no resuelven sino agravan el problema mundial. El Tribunal escuchó perturbadoras pruebas de testigos sobre los graves efectos para la salud el vivir en lugares contaminados por las industrias del carbón, el petróleo y el gas. ${ }^{51}$

b) Financiación de la Naturaleza y REDD+: revisa cómo el tratamiento de mercado de bosques y biodiversidad afecta a poblaciones locales y vulnera a la naturaleza. El Tribunal dictaminó que estos sistemas no reconocían que los seres humanos son parte integral e inseparable de una comunidad terrestre viviente, y que los que comerciaron con "créditos" de carbono o biodiversidad estaban violando los derechos de la naturaleza y fallando en su deber de asegurar que la búsqueda del bienestar humano contribuya al bienestar de la Madre Tierra.

c) Minería de Lignito - Bosque Hambach Alemania: la mina de lignito cerca de Bonn ha creado el agujero más grande de Europa, y a medida que se expande está destruyendo pueblos enteros y el antiguo bosque de Hambach. El bosque existe desde hace 12000 años, contiene árboles de 800 años y alberga 142 especies protegidas. Solo quedan unos $7 \mathrm{~km}^{2}$ de los $60 \mathrm{~km}^{2}$ originales. El Tribunal dictaminó que la expansión de la mina debía detenerse de inmediato y que Alemania debía reconocer los derechos de la naturaleza por ley a fin de impedir tales proyectos en el futuro.

48 Todos los testimonios se pueden consultar en Dan Bacher, "Tribunal Considers Rights of Nature in Imperiled San Francisco Bay-Delta", Daily Kos, May 02, 2016, acceso el 24 de abril de 2017, http://www.dailykos.com/stories/2016/5/2/1522252/-Tribunal-Considers-Rights-of-Nature-in-Imperiled-San-Francisco-Bay-Delta

49 El Tribunal estuvo integrado por 7 jueces de alta calidad moral y ética: Tom BK Goldtooth, Cormac Cullinan, Osprey Orielle Lak, Alberto Acosta, Shannon Biggs, Simona Fraudatario y Fernando "Pino" Solanas.

50 "International Rights of Nature Tribunal in Bonn Findings", Global Alliance (10 de noviembre de 2017), acceso el 7 de febrero de 2018, https://therightsofnature.org/united-nations/rights-of-nature-tribunal-bonn-findings/

51 Testigos de Mauricio y Texas presentaron evidencia de los impactos de huracanes y ciclones; por ejemplo, en las secuelas del huracán Harvey, los hogares resultaron dañados, se suspendieron las restricciones ambientales y la gente tuvo que respirar humos tóxicos. 
d) Defensores de la Madre Tierra: analiza las persecuciones a los pueblos indígenas protectores del agua en Standing Rock (USA), del carbón en Rusia y al pueblo Sámi en Suecia. El Tribunal escuchó cómo los pueblos indígenas, que usaban medios pacíficos para defender el agua y la Madre Tierra, son enfrentados con violencia y nunca fueron consultados. Las pruebas demostraron que el oleoducto de acceso Dakota disminuiría la calidad de vida de las minorías de los pueblos indígenas, especialmente en relación con el carácter sagrado del agua y las zonas sagradas y tomó nota de la historia actual de violaciones sistemáticas de los derechos de los pueblos indígenas, reiterando que todo el mundo tiene el deber de defender a quienes protegen los derechos de la Madre Tierra.

e) Escasez de agua en Almería, España: a causa de la producción industrial de aceitunas, el Tribunal dictaminó que la extracción de grandes cantidades de agua de los acuíferos de la región española de Almería, principalmente para regar grandes plantaciones intensivas de olivos, es una violación de los derechos de los ríos y sistemas ecológicos de Almería y de los derechos humanos de los pueblos locales, por lo cual debía cesar el cultivo intensivo de aceitunas en esa región. Este caso ilustra las consecuencias de tratar el agua como una mercancía que puede ser monopolizada en lugar de reconocer el agua como una fuente vital de vida, que debe ser respetada y protegida al más alto nivel. Aunque este caso se centra en un área específica, es un ejemplo de lo que está sucediendo en muchas partes del mundo, y los principios son universales.

f) Amenazas a la Amazonía: referido a la Amazonía ecuatoriana con el caso Sarayaku; a la Amazonía brasilera, el grave problema de TIPNIS en Bolivia y el problema en Montaña de Oro, en Guyana Francesa. El Tribunal decidió escuchar un número de casos de diferentes partes de la Amazonía simultáneamente para considerar las amenazas al ecosistema amazónico de una manera holística. Esto incluyó testimonios sobre la enorme mina propuesta en la Guayana Francesa y de comunidades de Brasil, Bolivia y Ecuador. Es evidente que este ecosistema vital es un reservorio de vida, hogar de muchos pueblos y parte esencial del mantenimiento de la estabilidad climática mundial. Escuchó denuncias de violaciones de los derechos de la Madre Tierra derivadas de la propuesta de construcción de una importante carretera a través del área protegida TIPNIS en Bolivia y de la explotación petrolera en el área con gran preocupación, en particular porque la Declaración Universal de los Derechos de la Madre Tierra fue proclamada en Bolivia en 2010 y dicho país ha defendido los derechos de la naturaleza a nivel internacional. El Tribunal decidió que deseaba reunir más pruebas de todos los interesados, incluido el Estado boliviano, y, de ser posible, enviar una delegación en misión de investigación a Bolivia. También decidió pedir al Gobierno boliviano que imponga una moratoria, como medida cautelar, en la construcción de la carretera y los puentes propuestos a través de TIPNIS y en la exploración petrolera en TIPNIS o cerca de TIPNIS, hasta que el Tribunal haya terminado su trabajo. 
h) Implicaciones de los Acuerdos de Libre Comercio en la Naturaleza: expertos de Canadá, Alemania, Sudáfrica y Puerto Rico testificaron que los Tratados de Libre Comercio (TLC) son los impulsores de una economía insostenible basada en los combustibles fósiles, la privatización, la mercantilización y la esclavitud legalizada de toda la vida en la Tierra. Dichos Acuerdos son jurídicamente vinculantes y tienen precedencia sobre los compromisos no vinculantes contraídos en virtud del Acuerdo de París. Incluso se puede impedir que los Estados aprueben nuevas leyes para proteger los ecosistemas si los tribunales establecidos bajo los Mecanismos de Solución de Controversias del Estado Inversionista deciden que son "barreras al comercio". El Tribunal dictaminó que los Tratados de Libre Comercio dan lugar a violaciones de los derechos de la naturaleza y que sus disposiciones deben considerarse nulas.

\section{Conferencia de los Derechos de la Tierra, abril 2017}

El 21 y 22 de abril del 2017 se celebró, en Sigtuna, Suecia, la Conferencia de los Derechos de la Tierra, a la que concurrieron diferentes personalidades provenientes de cinco continentes, de doce países y de pueblos indígenas como el pueblo Sami en Escandinavia, el pueblo Sarayaku y la nación quechua de Sudamérica. Todos los participantes suscribieron una Declaración en la que reconocieron y apoyaron la necesidad de una cosmovisión centrada en la Tierra, acentuando la interconexión de todos los seres, así como la urgente necesidad de implementarla en los sistemas legales. Asimismo, se comprometieron a vivir en armonía con la naturaleza, entre y con los hombres, así como a la cocreación de una cultura común de los derechos de la Tierra. Por otro lado, declararon ser el cambio del mundo a través de: aprender a gobernar en alineación con las leyes de la naturaleza; escuchar y hablar por la naturaleza, conectar y cooperar a través de las fronteras, ponerse de pie y tomar acción por los derechos de la Tierra. En esta Declaración hacen un llamamiento a todos los pueblos, organizaciones y Gobiernos para que se unan en esta gran empresa y tomen las medidas adecuadas. Llamamiento que hacen extensivo a las Naciones Unidas para que adopten la Declaración Universal sobre los Derechos de la Madre Tierra para el bienestar de la comunidad de la Tierra y de las generaciones futuras. ${ }^{52}$

\section{Declaración Universal de los Derechos de los Ríos}

En 2017, cuatro ríos obtuvieron personalidad jurídica, el río Whanganiu (o "Te Awa Tupua") reconocido como "un todo indivisible y vivo" y "una persona legal", el tribunal supremo de Uttarakhand declaró a los ríos Ganga (o Ganges) y Yamuna "con la condición de persona jurídica con todos los derechos, obligaciones y responsabilidades correspondientes”, una sentencia de la Corte Constitucional de Colombia por la que se estableció que la cuenca

52 "The Earth Rights Conference 2017", April 21-22 in Sigtuna, Sweden, acceso el 23 de junio de 2017, http://www.earthrightsconference.org/ 
del río Atrato posee derechos a "protección, conservación y recuperación”, y un fallo de una Corte Provincial de Ecuador haciendo cumplir los derechos constitucionales del río Vilcabamba y llamando a su remediación y rehabilitación. Asimismo, los Gobiernos de todo el mundo han comenzado a reconocer y hacer cumplir los derechos de la naturaleza, incluyendo las reformas constitucionales de Ecuador, 2010 y 2012, leyes nacionales en el Estado Plurinacional de Bolivia, la reforma constitucional de la Ciudad de México (programada para entrar en vigor en septiembre de 2018) y docenas de decretos sobre derechos de la naturaleza en los Estados Unidos. En virtud de lo anteriormente advertido, la organización Earth Law Center y sus asociadas están comprometidas en lograr personalidad jurídica para más ríos. Para establecer derechos para todos los ríos, dicha organización, con la colaboración de expertos en todo el mundo, ha redactado un proyecto de Declaración Universal de los Derechos de los Ríos, actualmente abierta a la firma. El mismo contiene 9 artículos y principalmente declara que todos los ríos son entidades vivientes que poseen derecho de acceso a la justicia, que deberán tener como mínimo los siguientes derechos fundamentales: derecho al flujo, a ejercer sus funciones esenciales con el ecosistema, a estar libre de toda contaminación, a alimentar y ser alimentado por sus afluentes, a biodiversidad nativa y a la restauración. Estos derechos tienen por objeto garantizar no solo la salud de los ríos, sino también la de las cuencas de las que forman parte. Establece además que el interés superior de los ríos debe ser evaluado y considerado como un elemento esencial y que para asegurar la completa implementación y la aplicación de estos principios, cada río tendrá derecho al nombramiento independiente de uno o más guardianes legales, que actúen únicamente en nombre de los derechos del río, con al menos un guardián legal como representante indígena de aquellos ríos de los cuales dependen las comunidades indígenas. ${ }^{53}$

\section{INSTRUMENTOS JURÍDICOS A NIVEL REGIONAL}

\section{Unión Europea}

El 29 de marzo de 2017, Nature’s Rights —una organización sin ánimo de lucro que busca establecer la personalidad jurídica y los derechos de los ecosistemas y las especies - celebró un acto en el Parlamento Europeo en Bruselas para lanzar su iniciativa en Europa y explorar las posibilidades que otorgaban los derechos de la naturaleza como una herramienta útil para ayudar a aprovechar la naturaleza y a alcanzar los objetivos europeos de biodiversidad. Luc Bas, director de la Oficina Regional Europea de la UICN, ofreció uno de los discursos principales compartiendo las opiniones de la Unión al reconocer claramente la importancia de los derechos de la naturaleza como la WCC-2012 — Resolución 100 "Incorporación de los Derechos de la Naturaleza como punto focal de organización en la toma de decisiones de

53 La Declaración completa, así como si se desea firmarla se encuentra en Earth Law Center, "Declaración Universal de los Derechos de los Ríos", Earth Law Center, acceso el 8 de febrero de 2018, https://www.earthlawcenter.org/river-rights 
la UICN"-, la cual fue adoptada en el Congreso Mundial de la Naturaleza de la UICN de 2012 en Jeju. La Resolución invita a la UICN y a sus miembros a promover el desarrollo de una Declaración Universal de los Derechos de la Naturaleza como primer paso hacia la reconciliación entre los seres humanos y la Tierra. Desde entonces, los derechos de la naturaleza también han sido mencionados en el Programa Mundial de la UICN 2017-2020, adoptado en el Congreso Mundial de la Naturaleza de la UICN de 2016 en Hawái. ${ }^{54}$ Actualmente se encuentra trabajando, conjuntamente con el Parlamento Europeo, en el borrador de Directiva de Protección de los Derechos de la Naturaleza. En el artículo 2 - definiciones- define a la Tierra como un sistema vivo dinámico que comprende una comunidad indivisible de todos los sistemas y organismos vivos, interrelacionados, interdependientes y complementarios, que comparten un destino. Conforme el artículo 4, la naturaleza, incluyendo la Tierra, los ecosistemas, los hábitats naturales, los especies biológicos y el clima atmosférico, posee personalidad jurídica. Enumera una lista no taxativa de derechos: a la vida y a la existencia, a mantener la integridad de sus ciclos naturales y procesos vitales, al hábitat, a evolucionar naturalmente, a preservar la diversidad de la vida, y la variedad de los seres que comprenden la naturaleza, a la preservación de los ciclos del agua y su existencia en cantidad y calidad necesarias para sostener la vida y a una restauración oportuna y efectiva. Cualquier conflicto entre los derechos de la naturaleza y los de cualquier otra persona se resolverá de manera que mantenga la integridad, el balance, la salud y el equilibrio de la naturaleza como fundamento de la vida. En el artículo 5-Derechos procesales de la naturaleza - determina que posee el derecho fundamental a la defensa, protección y a hacer valer sus derechos por cualquier persona física individual o colectivamente o por cualquier organización gubernamental o no gubernamental de la Unión Europea. ${ }^{55}$ En cuanto a los animales, la Unión Europea muestra una creciente sensibilización en proteger y respetar a los animales, en gran medida propiciada por los avances científicos que constatan empíricamente su naturaleza sensible. ${ }^{56} \mathrm{El}$ derecho, expresión de la sociedad, se ha hecho eco de esta tendencia, y si bien tradicionalmente las normas pretendían evitar el maltrato físico y establecer obligaciones de mantenerlos en buenas condiciones higiénico-sanitarias, actualmente la protección de los animales ha cobrado una

54 Unión Internacional para la Conservación de la Naturaleza UICN, “Envisioning a world that considers nature's rights: An introductory discussion in Europe”, UICN (31 de marzo de 2017), acceso el 27 de abril de 2017, https://www.iucn. org/news/europe/201703/envisioning-world-considers-nature\%E2\%80\%99s-rights-introductory-discussion-europe

55 Draft Directive ECI for Rights of Nature by Mumta Ito (with special thanks to Colin Robertson and Michelle PerrinTaillat for their contribution), Nature's Rights, acceso el 10 de junio de 2017, http://www.rightsofnature.eu/ECI-DraftDirective-Draft.pdf

56 La legislación comunitaria más temprana sobre protección de los animales data de hace más de 40 años, con la adopción en 1974 de una Directiva sobre aturdimiento de los animales antes de su sacrificio, actualizada posteriormente con la Directiva 93/119/CEE. Desde entonces, ha sufrido una evolución y notable ampliación hasta la situación actual, en la que varias docenas de normas se ocupan más o menos directamente de respetar las 5 "libertades básicas" de los animales: no sufrir molestias; no padecer hambre ni sed; no sufrir miedo ni angustia; ni dolor, heridas o enfermedad; y libertad para expresar su comportamiento natural. 
nueva dimensión, que puede condensarse en el concepto de bienestar animal. ${ }^{57}$ Sin embargo, no se les reconoce derechos ni se les otorga el estatus jurídico de sujetos de derechos, pero muchos autores, entre ellos Elena López-Almansa Beaus consideran que, mientras se avanza en otorgarles derechos como seres sintientes, este tipo de protección actual es oportuna pues abandonarlos a su suerte hasta que cese su estatus de "propiedad" agravaría, sin duda, su situación hasta límites insospechados. De hecho, la Comisión Europea ha adoptado el primer "Plan de Acción Comunitario sobre Protección y Bienestar de los Animales 2006-2010" (AWAP, Animal Welfare Action Plan) y en enero del 2012 una nueva estrategia cuatrienal (2012-2015) con el objetivo de mejorar el bienestar animal. ${ }^{58}$

\section{Organización de Estados Americanos (OEA)}

En el ámbito americano, la Corte Interamericana de Derechos Humanos ${ }^{59}$ abordó indirectamente el tema de la naturaleza, relacionándola con los derechos de los pueblos indígenas, en numerosos casos. ${ }^{60}$ Pero en el caso "Pueblo Indígena Kichwa de Sarayaku vs. Ecuador" del 27 de junio de 2012, destacó el profundo lazo cultural, inmaterial y espiritual que el Pueblo Sarayaku mantiene con su territorio, en particular, las características específicas de su "selva viviente" (Kawsak Sacha) y la relación íntima entre esta y sus miembros. De acuerdo con la cosmovisión del pueblo Sarayaku, el territorio está ligado a un conjunto de significados: la selva es viva y los elementos de la naturaleza tienen espíritus (supay) que se encuentran conectados entre sí y cuya presencia sacraliza los lugares. ${ }^{61}$ En relación con las afectaciones al

57 El bienestar animal, entendido en sus justos términos, consiste en proporcionar a estos seres vivos unas condiciones de vida adecuadas a sus necesidades fisiológicas y de comportamiento, que no se satisfacen simplemente con alimentación, limpieza o alojamiento, sino que se requiere que todo ello vaya referido a la condición etológica. Parte, por tanto, de la naturaleza sensible de los animales e impone al hombre la obligación, cuanto menos ética, de hacer todo lo posible por evitar y minimizar los supuestos en que son sometidos a situaciones que les generan sufrimiento físico o psíquico.

58 Elena López-Almansa Beaus, "Legislación europea sobre protección de los animales tras el Plan de Acción 2006-2010", Revista de Bioética y Derecho, sección Bioética Animal, 9 (2007).

59 Recordamos que la Convención Americana sobre Derechos Humanos, con jerarquía constitucional a partir de la reforma constitucional argentina de 1994, establece como órganos de protección y promoción de los derechos humanos a la Comisión Interamericana de Derechos Humanos y a la Corte Interamericana de Derechos Humanos.

60 Los casos son: Comunidad Mayagna (Sumo) Awas Tingni vs. Nicaragua. Fondo, Reparaciones y Costas. Sentencia de 31 de agosto de 2001, Comunidad Moiwana vs. Surinam. Excepciones Preliminares, Fondo, Reparaciones y Costas. Sentencia 15 de junio de 2005, Comunidad Indígena Yakye Axa vs. Paraguay. Fondo Reparaciones y Costas. Sentencia 17 de junio de 2005, Comunidad Indígena Sawhoyamaxa vs. Paraguay. Fondo, Reparaciones y Costas. Sentencia de 29 de marzo de 2006 y Pueblo Saramaka vs. Surinam. Excepciones Preliminares, Fondo, Reparaciones y Costas. Sentencia de 28 de noviembre de 2007.

61 Sintéticamente, los hechos que dieron lugar a la presentación fueron los siguientes: el 26 de julio de 1996 fue suscrito un contrato de participación para la exploración de hidrocarburos y explotación de petróleo crudo en el "Bloque 23" entre la Empresa Estatal de Petróleos del Ecuador (PETROECUADOR) y el consorcio conformado por la Compañía General de Combustibles S. A. (CGC) y la Petrolera Argentina San Jorge S. A. El espacio territorial otorgado en el contrato para ese efecto comprendía una superficie de 200000 ha, en la que habitan varias asociaciones, comunidades y pueblos indígenas, entre ellas Sarayaku, cuyo territorio ancestral y legal abarcaba un $65 \%$ de los territorios comprendidos en el Bloque 23. De acuerdo con las disposiciones del contrato celebrado en 1996 entre PETROECUADOR y la compañía CGC, la fase de exploración sísmica tendría una duración de cuatro años — con posibilidades de prórroga hasta por dos años- desde 
territorio Sarayaku, la Compañía General de Combustibles S. A destruyó al menos un sitio de especial importancia en la vida espiritual de los miembros del pueblo Sarayaku, en el terreno del Yachak César Vargas. Del mismo modo, abrió trochas sísmicas, habilitó siete helipuertos, destruyó cuevas, fuentes de agua, y ríos subterráneos, necesarios para consumo de agua de la comunidad; taló árboles y plantas de gran valor ambiental, cultural y de subsistencia alimentaria de Sarayaku. Todos estos trabajos ocasionaron la afectación y suspensión de actos y ceremonias ancestrales culturales. El 19 de diciembre de 2003 la Asociación del pueblo Kichwa de Sarayaku (Tayjasaruta), el Centro de Derechos Económicos y Sociales (CDES) y el Centro por la Justicia y el Derecho Internacional (CEJIL) denunciaron todo este accionar, junto con las amenazas y hostigamiento a través de una petición ante la Comisión Interamericana de Derechos Humanos, conforme lo dispuesto por el Pacto de San José de Costa Rica, y el 6 de julio de 2004, a solicitud de la Comisión, el Tribunal ordenó medidas provisionales a favor del pueblo Sarayaku y sus miembros, de conformidad con los artículos 63.2 de la Convención y 25 del Reglamento de la Corte. Finalmente, el 26 de abril de 2010 la Comisión Interamericana de Derechos Humanos presentó ante el Tribunal la demanda contra el Ecuador. La sentencia fue dictada una vez concluido el proceso y luego de que una delegación del Tribunal, encabezada por su presidente, efectuara, en abril de 2012, por primera vez en la historia de su práctica judicial, una diligencia en el lugar de los hechos. Durante la misma, el Estado reconoció su responsabilidad internacional y expresó su compromiso e interés en buscar formas de reparación. El 27 de junio de 2012, la Corte Interamericana de Derechos Humanos declaró, por unanimidad, que el Estado del Ecuador era responsable por la violación de los derechos a la consulta, a la propiedad comunal indígena, a la identidad cultural, por haber puesto gravemente en riesgo los derechos a la vida e integridad personal, el derecho a la propiedad comunal y por la violación de los derechos a las garantías judiciales y a la protección judicial todos ellos reconocidos respectivamente en los términos de los artículos 21, 1.1, 2, 4.1, 5.1, 1.1, 218.1 y 25 de la Convención Americana, en perjuicio del pueblo

\footnotetext{
que el Ministerio de Energía y Minas aprobara el estudio de impacto ambiental. La Compañía CGC subcontrató a otra empresa para la realización de un plan de impacto ambiental para la prospección sísmica, el cual fue realizado en mayo de 1997 y aprobado el 26 de agosto siguiente por el Ministerio de Energía y Minas. Este estudio no incluyó a Sarayaku. En el año 2002, la Asociación de Sarayaku envió una comunicación al Ministerio de Energía y Minas en que manifestó su oposición a la entrada de las compañías petroleras en su territorio ancestral. Entre los meses de octubre de 2002 y febrero de 2003, los trabajos de la empresa petrolera avanzaron un $29 \%$ en el interior del territorio de Sarayaku. En ese período, la empresa CGC cargó 467 pozos con aproximadamente 1433 kilogramos del explosivo "pentolita", tanto a nivel superficial como a mayor profundidad. Al momento de dictar la sentencia, los explosivos sembrados permanecían en el territorio de Sarayaku. A raíz de tales actividades y ante el ingreso de la CGC al territorio de Sarayaku, la comunidad paralizó sus actividades económicas, administrativas y escolares, con el propósito de resguardar los límites del territorio para impedir la entrada de la CGC. Entre febrero de 2003 y diciembre de 2004 fueron denunciados una serie de hechos de presuntas amenazas y hostigamientos realizados en perjuicio de líderes, miembros y un abogado de Sarayaku. El 6 de febrero de 2003, la Asociación de la Industria Hidrocarburífera del Ecuador informó que la CGC declaró un estado de "fuerza mayor" y suspendió los trabajos de exploración sísmica.
} 
Sarayaku. ${ }^{62}$ En lo referente al presente trabajo, en su testimonio ante la Corte Interamericana de Derechos Humanos, don Sabino Gualinga, líder político y guía espiritual del pueblo originario kichwa de Sarayaku, expuso ante el Tribunal lo que su pueblo llama kawsak sacha, o "la selva viviente":

las montańas, los árboles, los pantanos y los ríos son llaktas, es decir, "pueblos" o "ciudades" que conforman una compleja arquitectura cosmológica que alberga todo tipo de seres, tanto humanos como no humanos, profundamente entrelazados y mutuamente constitutivos e interdependientes. Kawsak sacha es el territorio de los Amasanga y los Sacha Runa, el refugio de jaguares, pumas y jabalíes, así como fuente de agua, alimento y medicina para las comunidades locales, es decir, el sustrato material a partir del cual el pueblo de Sarayaku forja su vida cotidiana, su cultura y su historia. ${ }^{63}$

Con respecto a los explosivos, afirmó que "para los extraños estos territorios no tienen vida, pero para los pueblos que habitamos aquí están vivos. Yo quisiera saber si se permitiría poner explosivos en Carondelet, el Palacio de Gobierno, o en la Casa Blanca. ¿Cómo reaccionarían los ciudadanos si tuvieran debajo de su casa miles y miles de kilos de explosivos?”. ${ }^{64}$ "El bosque vive y piensa. Los humanos no somos los únicos con capacidad para interpretar el mundo. Todos los seres vivos lo hacen. Continuamente interpretan y representan el mundo que habitan [...]. El bosque es una vasta ecología de seres pensantes engendradora de futuros.". ${ }^{65}$ Posteriormente, estos principios fueron tenidos en cuenta en otros casos. ${ }^{66}$

Desde la perspectiva ecológica, es de destacar las características geológicas de la Geo Amazonía, ya que todos los años recibe decenas de millones de toneladas de polvo proveniente de las tormentas de arena del desierto del Sahara. Este fenómeno atmosférico desempeña un papel crucial en el mantenimiento de la dinámica ecológica de la selva tropical más grande del mundo. A causa de las intensas precipitaciones y de las inundaciones estacionales, los suelos de la selva se desmineralizan y se reduce la concentración de nutrientes necesarios para el crecimiento y la salud de la vegetación, deficiencia que se compensa en parte mediante las nubes de polvo, rico en minerales, que se originan en el desierto africano. ${ }^{67}$ El flujo de nutrientes

62 Corte Interamericana de Derechos Humanos, Pueblo Indigena Kichwa de Sarayaku vs. Ecuador (sentencia de 27 de junio de 2012, CIDH), acceso el 15 de junio de 2017, http://www.corteidh.or.cr/docs/casos/articulos/seriec_245_esp.pdf

63 Ursula Biemann y Paulo Tavares, Forest Law-Selva Juridica. (Estados Unidos: Eli and Edythe Broad Art Museum, Michigan State University, 2014), 20.

64 Biemann, Forest Law-Selva Jurídica..., 38

65 Cualinga, citado por Biemann, Forest Law-Selva Jurídica..., 66.

66 Entre ellos, Pueblos Indígenas Kuna de Madungandí y Emberá de Bayano y sus Miembros vs. Panamá. Excepciones Preliminares, Fondo, Reparaciones y Costas. Sentencia de 14 de octubre de 2014, Comunidad Garífuna de Punta Piedra y sus Miembros vs. Honduras. Excepciones Preliminares, Fondo, Reparaciones y Costas. Sentencia de 08 de octubre de 2015 y Pueblos Kaliña y Lokono vs. Surinam. Fondo, Reparaciones y Costas. Sentencia de 25 de noviembre de 2015.

67 El polvo sahariano proviene en su mayor parte de una formación geológica llamada depresión de Bodélé, una cuenca gigantesca ubicada en la frontera sur del desierto, que hace miles de años estuvo cubierta por el "mar interior" que dio origen al lago Chad. Las corrientes de viento transportan la nube de arena hacia el suroeste sobre el Sahel, en dirección al 
que se ha establecido entre las tierras secas del Sahara y los suelos húmedos de la Amazonía revela vínculos inesperados entre estas dos geografías y ambientes, en apariencia separados y radicalmente opuestos. ${ }^{68}$ Además de ser refugio de biodiversidad del planeta, la Amazonía es una "reserva de carbono", un "océano verde" y una "fábrica de lluvia", funciona como una gigantesca fábrica de agua y como regulador global del clima. Al alejarse de este océano verde, las corrientes de aire llamadas "ríos voladores" empujan la humedad hacia las paredes de los Andes, desde donde son desviadas hacia la cuenca del Río de La Plata, y la lluvia producida por la Amazonía repone las reservas de agua de las represas hidroeléctricas y nutre los sistemas agrícolas, industriales y urbanos más importantes de Sudamérica. Es además un área de gran diversidad etnocultural, que alberga numerosas naciones indígenas. Del análisis de los párrafos anteriores, se puede concluir la coincidencia existente entre las filosofías ancestrales y las modernas teorías científicas: Gaia y Pachamama son dos diferentes maneras de denominar a una misma entidad, un ser viviente.

\section{CONCLUSIONES}

En el presente artículo se ha profundizado en el análisis de los instrumentos jurídicos a nivel internacional y regional que han receptado, aunque tímidamente, los derechos de la naturaleza. Si bien la mayoría de estos instrumentos no tiene fuerza vinculante, y muchos emanan de asociaciones civiles, se puede destacar una tendencia al reconocimiento de nuevos sujetos de derechos, ya sea la naturaleza como un todo como a cada uno de sus componentes, por ejemplo, los ríos, los ecosistemas y los animales. La estricta vigencia de los derechos de la naturaleza exige la existencia de marcos jurídicos internacionales adecuados, teniendo en consideración que los problemas ambientales son cada vez más temas que atañen a la humanidad en su conjunto. La tarea no es simple, se necesitan iniciativas tanto de la sociedad civil, de las organizaciones internacionales y de los Estados para proteger la vida del ser humano y la del planeta mismo. Muchos de los esfuerzos mencionados están preparando el camino hacia un cambio de cosmovisión, un cambio en la relación del ser humano con la naturaleza, tarea compleja si se considera que hay que vencer posiciones conservadoras y que se pone en juego profundos intereses económicos. Alberto Acosta reflexiona sobre los posibles caminos a seguir. Una opción sería que la ONU adhiera a la Declaración Universal de los Derechos de la Naturaleza. Bolivia consiguió un logro sustantivo con la declaración del agua como un derecho humano fundamental, lo que puede servir como otro punto de referencia. Sin embargo,

Golfo de Guinea, de donde escapa hacia el océano Atlántico, rumbo a Suramérica; parte del polvo se desvía al llegar a la desembocadura del río Amazonas, y a través del interior de su cuenca se esparce para alimentar vastas franjas de selva.

68 Como consecuencia del desarrollo de las ciencias ambientales, las tecnologías de detección remota y los modelos climáticos computarizados, así como también por los debates surgidos a raíz de la destrucción ambiental y del calentamiento global, cada vez se monitorean, investigan y mapean con mayor detalle los ecosistemas de la Amazonía, que ha sido equipada con una compleja red de vigilancia, constituida por una docena de gigantescas torres de monitoreo diseminadas a través de las más remotas zonas de la selva. 
también propone apoyar la adopción de los derechos de la naturaleza en otros ámbitos o en otros países a través de cambios constitucionales. ${ }^{69}$ Los invitamos, nuevamente, a la lectura de la tercera parte de la investigación referida al reconocimiento de la personalidad jurídica de la naturaleza y de los ríos en los derechos nacionales de algunos países, abarcando la Constitución Política, leyes, ordenanzas y jurisprudencia. Finalmente, recordando las palabras del célebre poeta, dramaturgo y novelista francés, Víctor Hugo: "Produce una inmensa tristeza pensar que la naturaleza habla mientras el género humano no la escucha. Primero fue necesario civilizar al hombre en su relación con el hombre. Ahora es necesario civilizar al hombre en su relación con la naturaleza y los animales" ${ }^{70}$

\section{REFERENCIAS}

- Aboglio, Ana María. "Declaración universal de los derechos animales". Ánima (25 de febrero de 2005). Acceso el 21 de abril de 2017. http://www.anima.org.ar/declaracion-universal-de-los-derechos-animales/

- Acosta, Alberto. "Hacia la Declaración Universal de los Derechos de la Naturaleza”. Revista afese 54, 54 (2010): 11-30.

- Asamblea General de las Naciones Unidas. "Informe del Secretario General. Armonía con la Naturaleza”. Sexagésimo séptimo período de sesiones. 17 de agosto de 2012. A/67/317.

"Resolución aprobada por la Asamblea General el 22 de abril de 2009 N $^{\circ}$ 63/278. Día Internacional de la Madre Tierra”. Sexagésimo tercer período de sesiones. 1 de mayo de 2009. A/RES/63/278.

"Resolución aprobada por la Asamblea General el 21 de diciembre de 2009 No 64/196. Armonía con la Naturaleza”. Sexagésimo cuarto período de sesiones. 12 de febrero de 2010. A/RES/64/196.

"Resolución aprobada por la Asamblea General el 21 de diciembre de 2012 No 67/214. Armonía con la Naturaleza”. Sexagésimo séptimo período de sesiones. 15 de marzo de 2013. A/RES/67/214.

- Bacher, Dan. "Tribunal Considers Rights of Nature in Imperiled San Francisco Bay-Delta”. Daily Kos, May 02, 2016. Acceso el 24 de abril de 2017. http://www.dailykos.com/

69 Alberto Acosta, "Hacia la Declaración Universal de los Derechos de la Naturaleza", Revista afese, 54, 54 (2010).

70 Víctor Hugo, En Voyage, Alpes et Pyrenees, citado por Eduardo Palomo Triguero, Cita-logía (Sevilla, España: Punto Rojo Libros, 2014), 66. 
stories/2016/5/2/1522252/-Tribunal-Considers-Rights-of-Nature-in-Imperiled-SanFrancisco-Bay-Delta

- Biemann, Ursula y Paulo Tavares. Forest Law-Selva Jurídica. Estados Unidos: Eli and Edythe Broad Art Museum, Michigan State University, 2014.

- Blanco Aristín, Ramón. "El Espíritu de la Declaración Universal de los Derechos Animales". Tendencias21 (31 de mayo de 2008). Acceso el 21 de abril de 2017. http://www.tendencias21.net/derecho/EL-ESPIRITU-DE-LA-DECLARACION-UNIVERSAL-DE-LAS-DERECHOS-ANIMALES_a45.html

- Boff, Leonardo. "Respeto y cuidado de la comunidad de la vida mediante el entendimiento, compasión y amor". En La Carta de la Tierra en Acción: Hacia un Mundo Sostenible, editado por Peter Blaze Corcoran, Mirian Vilela y Alide Roerink, 43-46. Ámsterdam: KIT Publisher BV, 2008.

- Bosselmann, Klaus y Prue Taylor. "La importancia de la Carta de la Tierra en el derecho internacional". En La Carta de la Tierra en Acción: Hacia un Mundo Sostenible, editado por Peter Blaze Corcoran, Mirian Vilela y Alide Roerink, 178-180. Ámsterdam: KIT Publisher BV, 2008.

- Clugston, Rick y John A. Hoyt. "La Carta de la Tierra y los animales". En La Carta de la Tierra en acción: hacia un mundo sostenible, editado por Peter Blaze Corcoran, Mirian Vilela y Alide Roerink, 155-156. Ámsterdam: KIT Publisher BV, 2008.

- Comisión Económica para América Latina CEPAL. "La ONU busca inclusión y transparencia en debate sobre cambio climático". Comunicado de prensa. CEPAL (22 de abril de 2010). Acceso el 21 de abril de 2017. HTTP://WWW.CEPAL.ORG/ES/COMUNICADOS/LA-ONU-BUSCA-INCLUSION-Y-TRANSPARENCIA-EN-DEBATE-SOBRE-CAMBIO-CLIMATICO

- Consejo Económico y Social. Foro Permanente para las Cuestiones Indígenas. "Estudio sobre la necesidad de reconocer y respetar los derechos de la Madre Tierra". 15 de enero de 2010. E/C.19/2010/4.

- "Cormac Cullinan Judges Ruling on Great Barrier Reef Case. Rights of Nature Tribunal - Quito Ecuador”. Global Alliance for the Rights of Nature (January 2014). Acceso el 30 de abril de 2017. http://therightsofnature.org/cormac-cullinan-great-barrier-reef-case/

- Corte Interamericana de Derechos Humanos. Pueblo Indigena Kichwa de Sarayaku vs. Ecuador (sentencia de 27 de junio de 2012, CIDH). Acceso el 15 de junio de 2017. http:// www.corteidh.or.cr/docs/casos/articulos/seriec_245_esp.pdf 
- "Día de la Tierra: la alfabetización ambiental y climática es la cura". Infobae (21 de abr. de 2017), sección RSE\&Sustentabilidad. Acceso el 1 de agosto de 2017. http://www. infobae.com/economia/rse/2017/04/21/dia-de-la-tierra-la-alfabetizacion-ambiental-y-climatica-es-la-cura/

- Draft Directive ECI for Rights of Nature by Mumta Ito (with special thanks to Colin Robertson and Michelle PerrinTaillat for their contribution). Naturés Rights. Acceso el 10 de junio de 2017. http://www. rightsofnature.eu/ECI-DraftDirective-Draft.pdf

- Earth Law Center. "Declaración Universal de los Derechos de los Ríos". Earth Law Center. Acceso el 8 de febrero de 2018. https://www.earthlawcenter.org/river-rights

- "El polémico crudo de Canadá que muy pocos quieren". BBC Mundo, 29 de nov. de 2011. Acceso el 23 de abril de 2017. http://www.bbc.com/mundo/noticias/2011/11/111129_petroleo_alquitran_canada_am.shtml

- "El veredicto del Tribunal Ético por los Derechos de la Naturaleza, caso Yasunî". Global Alliance for the Rights of Nature (15 de agosto de 2014). Acceso el 21 de abril de 2017. http://therightsofnature.org/veredicto-del-tribunal-caso-yasuni/

- Gauger, Anja Mai Rabatel-Fernel, Louise Kulbicki, Damien Short y Polly Higgins. The Ecocide Project. Ecocide is the missing 5th Crime Against Peace. London: Human Rights Consortium, School of Advanced Study, University of London, 2013.

- Goldtooth, Tom. "Hydraulic Fracking Case Verdict, International Rights of Nature Tribunal, Lima, Peru, December 2014". Global Alliance for the Rights of Nature (December 6, 2014). Acceso el 22 de abril de 2017. http://therightsofnature.org/fracking-case-verdict/

- "Great Barrier Reef Verdict - Lima. International Rights of Nature Tribunal, Lima-Perú". Global Alliance for the Rights of Nature (December 2014). Acceso el 2 de mayo de 2017. http://therightsofnature.org/great-barrier-reef-verdict-lima/

- Higgins, Polly, Damien Short y Nigel South. "Protecting the planet: a proposal for a law of ecocide". Crime Law Soc Change 59 (2013): 251-266. ISSN 0925-4994.

- Hugo, Víctor. "Voyage, Alpes et Pyrenees". Citado por Eduardo Palomo Triguero. Cita-logia. Sevilla, España: Punto Rojo Libros, 2014.

- "International Rights for Nature Tribunal - Paris, December 4-5". Global Alliance for the Rights of Nature. Acceso el 30 de mayo de 2017. http://therightsofnature.org/rights-of-nature-tribunal-parisl

- "International Rights of Nature Tribunal in Bonn Findings". Global Alliance for the Rights of Nature (10 de noviembre de 2017). Acceso el 7 de febrero de 2018. https://therightsofnature.org/united-nations/rights-of-nature-tribunal-bonn-findings/ 
- López-Almansa Beaus, Elena. "Legislación europea sobre protección de los animales tras el Plan de Acción 2006-2010”. Revista de Bioética y Derecho, sección Bioética Animal, 9 (2007): 1-9.

- Mackey, Brendan. "La integridad ecológica: un compromiso hacia la vida en la Tierra". En La Carta de la Tierra en acción: hacia un mundo sostenible, editado por Peter Blaze Corcoran, Mirian Vilela y Alide Roerink, 67-71. Ámsterdam: KIT Publisher BV, 2008.

- Maloney, Michelle. "Finally Being Heard: The Great Barrier Reef and the International Rights of Nature Tribunal”. Griffith Journal of Law \& Human Dignity, 3 (2015): 40-58. ISSN: 2203-3114.

- Martínez, Adriana Norma y Adriana Margarita Porcelli. "Una nueva visión del mundo: la ecología profunda y su incipiente recepción en el derecho nacional e internacional (primera parte)". Lex año XV-I, n. 20 (2017): 395-440. ISSN 2313-1861. http://dx.doi. org/10.21503/lex.v15i20.1450

- ONU. "Carta Mundial de la Naturaleza”. 28 de octubre de 1982. A/37/L.4 y Add.1.

"La protección de la Madre Tierra, a debate en la ONU". Noticias ONU(21 de abril de 2017). Acceso el 5 de febrero de 2018. http://www.un.org/sustainabledevelopment/es/2017/04/la-proteccion-de-la-madre-tierra-a-debate-en-la-onu/

- Parrilla, Juan. "Monsanto, hallado culpable por daños a la salud y el ambiente, crímenes de guerra y ecocidio". Infobae (18 de abril de 2017). Sección Sociedad. Acceso el 2 de junio de 2017. http://www.infobae.com/sociedad/2017/04/18/monsanto-hallado-culpable-por-danos-a-la-salud-y-el-ambiente-crimenes-de-guerra-y-ecocidio/

- Prieto, Julio. "Juicio contra Chevron en el Ecuador" (17 de enero 2014). Acceso el 5 de mayo de 2017. http://therightsofnature.org/wp-content/uploads/Memorial-Caso-ChevronSP.pdf

- Ruiz, Pau. "El quinto crimen contra la paz". ecoavant.com (31 de enero de 2014). Acceso el 2 de junio de 2017. http://www.ecoavant.com/es/notices/2014/01/el-quinto-crimen-contrala-paz-1926.php\#

- Secretaría Internacional de la Carta de la Tierra. Iniciativa de la Carta de la Tierra. Folleto Informativo. San José de Costa Rica: Secretaria Internacional de la Carta de la Tierra, 2008.

- "The Earth Rights Conference 2017". April 21-22 in Sigtuna, Sweden. Acceso el 23 de junio de 2017. http://www.earthrightsconference.org/ 
- "Tribunal Offers Earth-Driven, Not Market-Driven, Solutions to Climate Change". Global Alliance for the Rights of Nature (Wednesday, December 9th, 2015). Acceso el 13 de junio de 2017. http://therightsofnature.org/ron-events/tribunal-offers-earth-driven-not-market-driven-solutions-to-climate-changel\#_ftn1

- Unión Internacional para la Conservación de la Naturaleza UICN. "Envisioning a world that considers nature's rights: An introductory discussion in Europe". UICN (31 de marzo de 2017). Acceso el 27 de abril de 2017. https:/www.iucn.org/news/europe/201703/envisioning-world-considers-nature $\% \mathrm{E} 2 \% 80 \% 99$ s-rights-introductory-discussion-europe

Recibido: $11 / 02 / 2018$

Aprobado: 14/04/2018 